\title{
Assessment of a Proximal Sensing-integrated Crop Model for Simulation of Soybean Growth and Yield
}

\author{
Ashifur Rahman Shawon ${ }^{1,+} \mathbb{D}^{\mathbb{D}}$, Jonghan Ko ${ }^{1, *} \mathbb{C}$, Bokeun Ha $^{1}$, Seungtaek Jeong ${ }^{1}$, \\ Dong Kwan Kim ${ }^{2}$ and Han-Yong Kim ${ }^{1}$ \\ 1 Department of Applied Plant Science, Chonnam National University, Gwangju 501-759, Korea; \\ ashifur.shawon@julius-kuehn.de (A.R.S.); bkha@chonnam.ac.kr (B.H.); jst5000@chonnam.ac.kr (S.J.); \\ hyk1020@jnu.ac.kr (H.-Y.K.) \\ 2 Jeonnam Agricultural Research and Extension Services, Naju 520-712, Chonnam Province, Korea; \\ kms1996@korea.kr \\ * Correspondence: jonghan.ko@jnu.ac.kr; Tel.: +82-62-530-2053 \\ + Current affiliation: Institute for Strategies and Technology Assessment, Julius Kühn-Institut, \\ Federal Research Centre for Cultivated Plants, 14532 Kleinmachnow, Germany.
}

Received: 8 December 2019; Accepted: 26 January 2020; Published: 28 January 2020

\begin{abstract}
A remote sensing-integrated crop model (RSCM) able to simulate crop growth processes using proximal or remote sensing data was formulated for simulation of soybean through estimating parameters required for modelling. The RSCM-soybean was then evaluated for its capability of simulating leaf area index (LAI), above-ground dry mass (AGDM), and yield, utilising the proximally sensed data integration into the modelling procedure. Field experiments were performed at two sites, one in 2017 and 2018 at Chonnam National University, Gwangju, and the other in 2017 at Jonnam Agricultural Research and Extension Services in Naju, Chonnam province, South Korea. The estimated parameters of radiation use efficiency, light extinction coefficient, and specific leaf area were $1.65 \mathrm{~g} \mathrm{MJ}^{-1}, 0.71$, and $0.017 \mathrm{~m}^{2} \mathrm{~g}^{-1}$, respectively. Simulated LAI and AGDM values agreed with the measured values with significant model efficiencies in both calibration and validation, meaning that the proximal sensing data were effectively integrated into the crop model. The RSCM reproduced soybean yields in significant agreement with the measured yields in the model assessment. The study results demonstrate that the well-calibrated RSCM-soybean scheme can reproduce soybean growth and yield using simple input requirement and proximal sensing data. RSCM-soybean is easy to use and applicable to various soybean monitoring projects.
\end{abstract}

Keywords: assessment; crop growth modelling; proximal; RSCM; soybean

\section{Introduction}

Monitoring crop growth conditions and yield could be beneficial to stakeholders, including researchers, agricultural policymakers, and on-farm decision-makers for smart farming and climate change impact analysis and mitigation [1]. Crop models are one of the best tools for the crop monitoring task as well as timely and cost-efficient decision-making. While empirical crop modelling is a practical methodology, the models can be limited to particular sites and periods due to their dependence on the ground measurement of fields of interest [2,3]. Process-based crop models can simulate biophysical processes in the soil-crop-atmospheric system for different regions, providing a continuous description of crop growth processes and development [4,5]. However, these models tend to be inadequate for observing large regions in detail or with a geospatial variation. Meanwhile, proximal or remote sensing (RS) is a practical and useful technique capable of identifying and monitoring crop growth conditions [6,7]; RS data can offer a timely, reliable, synoptic, and up-to-date sketch of actual crop 
growing conditions over a large area at multiple developmental stages during the crop-growing season. Vegetation indices (VIs) derived from RS are strongly related to the vegetation condition and above-ground dry mass (AGDM) of a crop species [8,9]. Crop growth and yield can be monitored only using crop growth and VI or yield and VI relationships, and some researchers have frequently applied the empirical modelling approach to determine the crop conditions and variables of interest from RS data [10,11]. However, applying the empirical model often has limitations due to its site-specific characteristics. Also, VIs obtained from satellite images can be applied upon atmospheric correction, mostly requiring extensive time-series data sets and having limited availability of remotely sensed information at a definite time interval [12].

Monitoring crop growth conditions and yield adopting any of the techniques mentioned above tends to require some detailed information on the crop (i.e., cultivar characteristics) and/or the field of interest (e.g., management and environmental conditions). A crop model integrated with RS can help the crop scouting practices. This integration approach likely improves estimation accuracy owing to advancement in both physical and empirical relationships between crop growth variables. Moreover, a crop simulation model incorporated with RS data can produce solid performances even with no data about the objective crop and field available except for RS information [13,14]. RS data assimilation in crop modelling has become widespread in crop growth and yield monitoring because of its improved simulation performance in crop growth and yield estimation and forecasting [15,16]. RS information can be integrated into a crop model in several ways: using a state variable directly obtained from RS information; updating state variables based on regression coefficients; re-initializing the model by changing initial conditions; and recalibrating the model by adjusting model parameters [17]. The GRAMI crop model proposed by Maas [18-20] employed a hybrid method of integrating RS information into a crop model to simulate growth and yield of gramineous staple crops (i.e., maize, sorghum, and wheat) based on a process modelling approach. This model was extended to simulate cotton lint yield [21]. The model was also updated to simulate rice growth for monitoring regional productivity and geographic variation [5]. The updated GRAMI model needs to be further extended to simulate other major crops, such as soybean, based on proximal or remote sensing information.

Soybean (Glycine max), a species of legume native to East Asia, is a globally important food crop as a primary provider of oil and protein [22]. Many researchers have studied simulating soybean growth and development for estimating and monitoring productivity. Distinguished work was the CROPGRO-soybean model [23] that can predict leaf area index (LAI), biomass, and grain yield. SOYGRO [24] was developed earlier as a process-based crop model by an interdisciplinary research group at the University of Florida to predict daily soybean growth, development, and pulse yield. The SOYWEED model [25] can also reproduce the growth of soybean competing with weeds. Sinclair [26] developed a model to simulate soybean growth and yield with the combination of carbon, nitrogen, and water-limited conditions. The SoySim model [27] was designed to simulate photosynthesis and biomass partitioning by using different phenological determinants. APSIM [28] is a model that can simulate soybean yield, improving risk management and adaptation through linking crop growth and soil processes. Problems related to most common models for simulating soybean are that they require either a large number of crop-specific inputs to execute the model or phenological determinants that are difficult to obtain and need expert supervision. It can be of assistance for crop model users to have a user-friendly soybean model that is executable with a simple input requirement.

It would add practical values to the scientific and industrial advancement in crop ecology to have an efficient monitoring system for soybean (i.e., one of the five main food crops) using the RS integrated crop modelling regime as an extended GRAMI version. Therefore, the objectives of this study were to (1) estimate the growth and yield parameters of soybean required for the model input; and (2) simulate the soybean growth responses using the estimated growth specific parameters and with a concept of using proximal or remote sensing data and simple inputs. The model calibration and validation processes were performed according to both LAI and VIs input options, assuming these variables of canopy growth would be commonly obtained. We also updated the model name 
to a common terminology as the Remote Sensing-Integrated Crop Model (RSCM) since the GRAMI (GRAMIneous) model definition is limited to grain crops only. We calibrated and evaluated RSCM to produce consistent simulation outputs for different crop characteristics and environments.

\section{Materials and Methods}

\subsection{Site Description}

Field experiments were performed to estimate crop-specific parameters and evaluate RSCM for simulating soybean growth and yield for two years (2017 and 2018) at Chonnam National University $\left(\mathrm{CNU}, 35^{\circ} 10^{\prime} \mathrm{N}, 126^{\circ} 53^{\prime} \mathrm{E} ; 33 \mathrm{~m}\right)$, Gwangju and one year (2017) at Jeonnam Agricultural Research and Extension Services (JARES, 35 $02^{\prime} \mathrm{N}, 126^{\circ} 83^{\prime} \mathrm{E} ; 37.0 \mathrm{~m}$ ) in Naju, Chonnam province, South Korea. These study sites belong to a typical East Asian monsoon climate zone, recording a yearly average rainfall of 1391-1520 $\mathrm{mm}$ for the last 20 years; most of the precipitation ( 60\%) occurred during the summer monsoon season (July-August). The topmost soil layers $(0-30 \mathrm{~cm})$ are classified as a loam at the CNU field and a silty clay loam at the JARES field, according to the soil characteristic map (http://soil.rda.go.kr/soil/) by the National Institute of Agricultural Sciences, South Korea. At the CNU site, four germplasms or cultivars of soybean each in 2017 (SS0903, SS0908, Daewon, and Poongsanamul) and 2018 (Hengbuk, Daewon, Daepung, and Poongsan) were sown on 22 June 2017 and 22 June 2018 with a randomized complete block design at three replications. At the JARES site, four soybean cultivars (Daewon, Haepum, Poongsanamul, and Taekwang) were likewise sown on 23 June 2017 with a randomized complete block design at three replications. The plant populations were 19.05 plants $\mathrm{m}^{-2}$ with a planting space of $0.70 \times 0.15 \mathrm{~m}$ at the CNU site and 22.22 plants $\mathrm{m}^{-2}$ with a planting space of $0.60 \times 0.15 \mathrm{~m}$ at the JARES site. Nitrogen $(\mathrm{N})$, phosphorus $(\mathrm{P})$, and potassium $(\mathrm{K})$ fertilizers were applied at $30 \mathrm{~N}, 30 \mathrm{P}$, and $34 \mathrm{~K} \mathrm{~kg} \mathrm{ha}^{-1}$, respectively.

Climate data at the CNU site were recorded using an automated weather station (WS-GP1, Delta-T Devices, Cambridge, UK), while those at the JARES site were obtained from the nearby $(\sim 7.3 \mathrm{~km})$ Automatic Weather Station by the Korea Meteorological Administration (https://data.kma.go.kr). At the CNU experimental site, the mean solar radiation values during the years 2017 and 2018 were 16.80 and $18.29 \mathrm{MJ} \mathrm{m}^{-2} \mathrm{~d}^{-1}$, respectively. The mean precipitation was $3.55 \mathrm{~mm} \mathrm{~d}^{-1}$ in 2017 and $7.76 \mathrm{~mm} \mathrm{~d}^{-1}$ in 2018. The average precipitation during the 2017 growing season was $\sim 13.24 \mathrm{~mm} \mathrm{~d}^{-1}$ with a total amount of $728.4 \mathrm{~mm}$, and in 2018, the average was $22.83 \mathrm{~mm} \mathrm{~d}^{-1}$ with a total amount of $958.9 \mathrm{~mm}$. Average relative humidity during the growing season was 78.41\% in 2017 and $76.08 \%$ in 2018. At the JARES site, the mean solar radiation and mean precipitation were $15.58 \mathrm{MJ} \mathrm{m}^{-2} \mathrm{~d}^{-1}$ and $2.52 \mathrm{~mm}$ $\mathrm{d}^{-1}$, respectively. The average precipitation during the growing season was $\sim 5.86 \mathrm{~mm} \mathrm{~d}^{-1}$ with a total amount of $697.0 \mathrm{~mm}$. The average relative humidity during the growing season was $87.94 \%$.

\subsection{Measurement of Soybean Growth Variables}

Soybean growth-specific variables such as LAI, AGDM, interception of photosynthetically active radiation (PAR), and canopy reflectance were measured at the different crop growth stages. LAI was measured on DOY 206, 215, 222, 244, 251, 261, 273, and 282 in 2017 and on DOY 198, 205, 213, 219, 231, 248, 275, and 287 in 2018 using an LAI-2200C (LI-COR, Inc., Lincoln, NE, USA). An LAI-2200C can be applied to measure canopy LAI in diffuse sunlight, even in daylight, using light-scattering correction with precise accuracy. It measures the LAI using a fish-eye lens based on gap fraction [29].

PAR intercepts were measured using a 1-m long line quantum sensor (LI-190R, LI-COR, Inc.) between two hours before and after the solar noon at an approximate time interval of seven days. Measurements were taken two to four times above the canopy and four times below the canopy; the measurements below the canopy were made placing the sensor perpendicular to the row. Finally, the fraction of light interception was estimated as a mean for all the measurements for the whole population.

The plant samples were harvested for estimating AGDM on DOY 205, 223, 247, and 284 in 2017 and on DOY 198, 205, 212, 221, and 289 in 2018 except root in each plot. The plant samples were 
then separated into leaves, stem, and pods and dried in an oven at $70{ }^{\circ} \mathrm{C}$ for one to two weeks, depending on the sample condition. Plants were sampled to estimate biomass partitioning by means of photosynthesis utilizing PAR.

\subsection{Ground-based Proximal Sensing}

A hand-held multispectral radiometer, MSR16R (CROPSCAN Inc., Rochester, MN, USA), was employed to survey the canopy reflectance as a percentage to determine crop growth status at critical growth stages. The hand-held ground-based system consists of a multispectral radiometer (MSR), a data logger controller, a terminal, a telescopic support pole, attaching cables, and operating software. MSR16R has several advantages in that it is easy to use and economical compared with most hyperspectral radiometers. Upward and downward sensors measure both incoming and reflected radiation nearly simultaneously, which provides useful reflectance readings in lightly cloudy conditions with incident irradiance down to approximately $300 \mathrm{~W} \mathrm{~m}^{-2}$. This indicates that measuring reflectance is possible in the nonhomogeneous sky conditions that often occur in monsoon regions, such as East Asia, including our study site. The MSR 16 model used in this study was equipped with 16 waveband filters in the 450-1750 nm region; more detail on the theory of operation and the system components, operation, and characteristics can be found on the CROPSCAN website (http://www.cropscan.com/). Measurements were taken on DOY 206, 215, 222, 244, 251, 261, 273, and 282 in 2017 and DOY 198, 205, $213,219,231,248,275$, and 287 in 2018 to estimate four VIs in the clear sky during one hour before and after the solar noon. The following four VIs were adopted in the RSCM model. Normalized difference vegetation index, NDVI [30], optimized soil adjusted vegetation index, OSAVI [9], modified triangular vegetation index, MTVI1 [8], and renormalized vegetation index, RDVI [31] were determined using the following formulas:

$$
\begin{gathered}
\text { NDVI }=\left(R_{800}-R_{660}\right) /\left(R_{800}+R_{660}\right) \\
\text { RDVI }=\left(R_{800}-R_{660}\right) / \sqrt{\left(R_{800}+R_{660}\right)} \\
\text { OSAVI }=\left(R_{800}-R_{660}\right) /\left(R_{800}+R_{560}+0.16\right) \\
\text { MTVI1 }=1.2 \cdot\left[1.2 \cdot\left(R_{800}-R_{560}\right)-2.5 \cdot\left(R_{660}-R_{560}\right)\right]
\end{gathered}
$$

where R800, R660, and R560 represent reflectance at 800, 660, and $560 \mathrm{~nm}$, respectively.

\subsection{Model Description}

RSCM (previously GRAMI) [20] is a simple crop model that simulates growth and yield of grain crops using frequent RS observations and readily determinable specific crop growth parameters based on a radiation use efficiency approach [32]. RSCM was designed for modelling gramineous crops (i.e., maize, sorghum, and wheat), using simple inputs of weather variables and RS data, which was extended to simulate cotton [21] and rice [5]. RSCM reproduces canopy growth, development, and yield in four simple processes by integrating growth specific parameters (i.e., radiation use efficiency [RUE], specific leaf area [SLA], light extinction coefficient [k], base temperature, and leaf partitioning and senescence parameter).

The four processes of crop modelling (Figure 1a) comprise (1) accumulation of growing degree days (GDDs) using daily air temperature and crop base temperature, (2) absorption of PAR in the generated canopy LAI, (3) increase in daily AGDM by partitioning photosynthetic product, and (4) determining LAI partitioning parameters or senescence using the following equations. Daily change in GDD $(\Delta \mathrm{D})$ is calculated by subtracting daily average temperature $(\mathrm{T})$ from the base temperature $\left(\mathrm{T}_{\mathrm{b}}\right.$, $\left.10^{\circ} \mathrm{C}\right)$ of soybean [33] as follows:

$$
\Delta \mathrm{D}=\operatorname{Max}\left[\mathrm{T}-\mathrm{T}_{\mathrm{b}}, 0\right]
$$




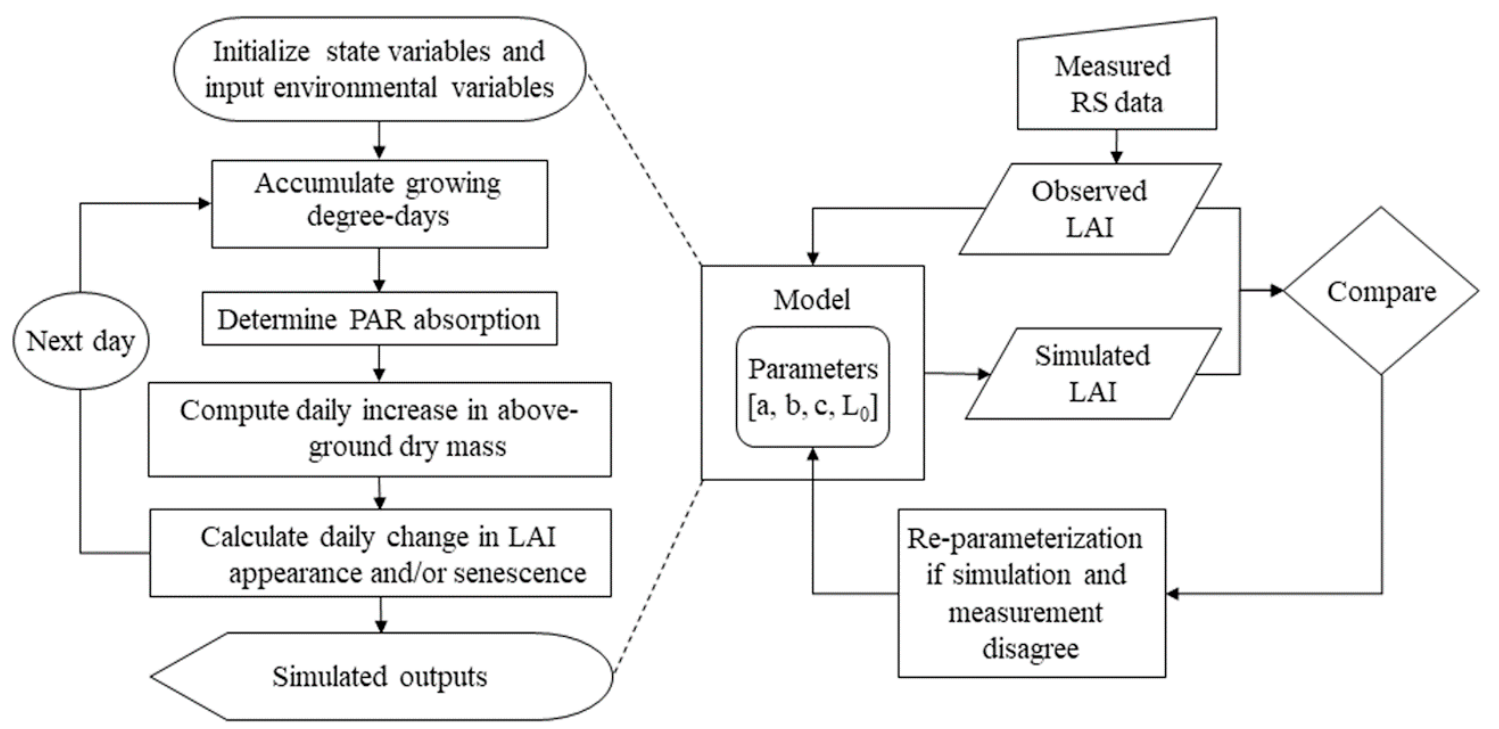

(a)

(b)

Figure 1. Diagrammatic representation of the remote sensing-integrated crop model (RSCM) model: (a) crop simulation procedure and (b) 'within-season calibration' for model parameterization using proximal or remote sensing information. LAI, PAR, and RS represent leaf area index, photosynthetically active radiation, and remote sensing, respectively.

Daily increase in $\operatorname{AGDM}(\Delta)$ is calculated as a function of RUE $(\varepsilon)$ and daily total intercepted PAR above the canopy $(\mathrm{Q})$ as follows:

$$
\begin{gathered}
\Delta \mathrm{M}=\varepsilon \cdot \mathrm{Q}, \\
\mathrm{Q}=\beta \cdot \mathrm{R} \cdot(1-\exp (-\mathrm{k} \cdot \mathrm{LAI}))
\end{gathered}
$$

where $Q$ is determined using the function of the fractional constant of solar radiation $(\beta)$ to calculate PAR, daily solar radiation (R), light extinction coefficient (k), and LAI of the canopy. The daily increase in LAI $(\Delta \mathrm{L})$ is calculated by integrating SLA or $\mathrm{S}, \Delta \mathrm{M}$, and the fraction of the $\Delta \mathrm{M}$ partitioned to new leaves $\left(P_{1}\right)$ using the following formula:

$$
\begin{gathered}
\Delta \mathrm{L}=\Delta \mathrm{M} \cdot P_{1} \cdot \mathrm{S}, \\
P_{1}=\operatorname{Max}[1-\mathrm{a} \cdot \exp (\mathrm{b} \cdot \mathrm{D}), 0]
\end{gathered}
$$

where $P_{1}$ is calculated using the above function where a and $\mathrm{b}$ are two parameters that control magnitude and shape of the function, and D is the cumulative GDD. The leaf senescence $\left(L_{s}\right)$ used in the model was formulated as follows:

$$
\begin{gathered}
\mathrm{L}_{\mathrm{s}}=\mathrm{c} \cdot\left(\Delta \mathrm{M}_{\mathrm{R}}-\Delta \mathrm{M}\right), \\
\Delta \mathrm{M}_{\mathrm{R}}=f_{\mathrm{b}} \cdot \mathrm{M}
\end{gathered}
$$

where $c$ is a parameter that controls the magnitude of the function; $\Delta \mathrm{M}_{\mathrm{R}}$ is daily maintenance respiration required to convert to biomass, and $\mathrm{M}$ is total AGDM; and $f_{\mathrm{b}}$ is the maintenance coefficient, which is defined as a hypothetical max value of $0.03 \mathrm{~d}^{-1}$. While the $f_{\mathrm{b}}$ value is theoretically determined as $\sim 1.5 \%$ of the existing dry weight of a crop, we set the max value, as the current model is designed to calibrate the maintenance respiration using the parameter $\mathrm{c}$. It is designed that LAI starts to senesce after reaching the maximum LAI. The senescence rate changes according to plant genetic traits and 
environmental conditions. Grain yield $(\Delta \mathrm{G})$ is partitioned from the fraction of $\Delta \mathrm{M}$ to grains using a dimensionless grain-partitioning function $\left(P_{2}\right)$ as follows:

$$
\begin{gathered}
\Delta \mathrm{G}=P_{2} \cdot \Delta \mathrm{M}, \\
P_{2}=\operatorname{Max}\left[1-P_{\mathrm{a}} \cdot \exp \left(P_{\mathrm{b}} \cdot f G_{\mathrm{D}}\right), 0\right]
\end{gathered}
$$

where $P_{\mathrm{a}}$ and $P_{\mathrm{b}}$ are two parameters in the function that controls the magnitude and slope, and $f G_{\mathrm{D}}$ is the grain-partitioning factor based on the cumulative GDD.

RSCM can adjust the model parameters and initial conditions that control crop growth variables, using the within-season calibration process to make an agreement between simulation and observation of readily observable state variables such as LAI or VI. This calibration process is performed by integrating observed values into the model using an iterative numerical procedure to mitigate the uncertainty in crop modelling due to the probable inaccurate measurement of state variables or inaccessibility (Figure 2b).

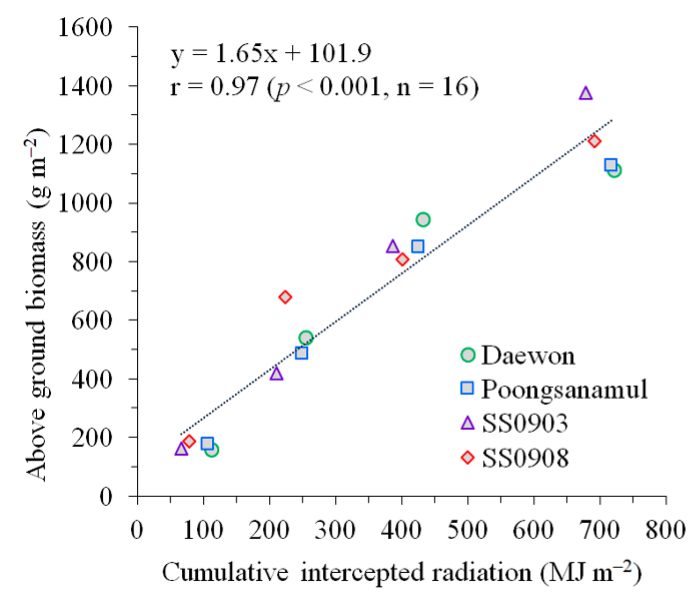

(a)

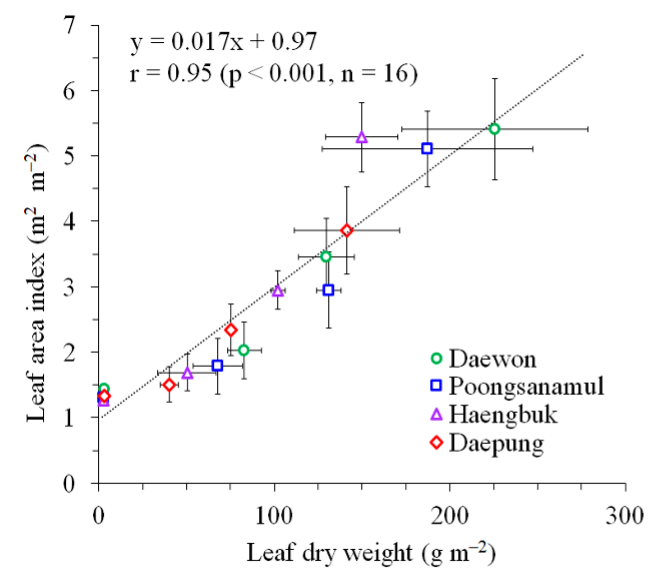

(b)

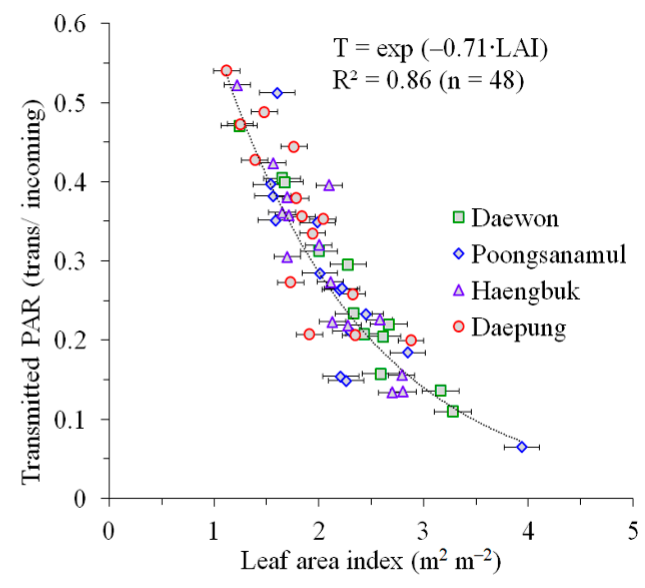

(c)

\begin{tabular}{|cccc|}
\hline Parameter & Symbol/acronym & Unit & Value \\
\hline $\begin{array}{c}\text { Radiation use } \\
\text { efficiency }\end{array}$ & $\varepsilon$ & $\mathrm{g} \mathrm{MJ}^{-1}$ & 1.65 \\
\hline $\begin{array}{c}\text { Specific leaf } \\
\text { area }\end{array}$ & SLA & $\mathrm{m}^{2} \mathrm{~g}^{-1}$ & 0.017 \\
\hline $\begin{array}{c}\text { Light extinction } \\
\text { coefficient }\end{array}$ & $\mathrm{k}$ & unitless & 0.71 \\
\hline
\end{tabular}

(d)

Figure 2. Determination of radiation use efficiency $(\varepsilon)$, specific leaf area (SLA), and light extinction coefficient $(\mathrm{k}): \varepsilon$ estimated from the linear regression relationship between the amounts of accumulated photosynthetically active radiation (PAR) absorbed by soybean canopies and above-ground dry mass (a); SLA from the linear regression relationship between leaf area index and leaf dry weight (b); $k$ derived from the exponential regression between transmitted and incoming PAR $(T)$ and leaf area index, LAI (c); and determined values of $\varepsilon$, SLA, and $\mathrm{k}(\mathbf{d})$. The data were obtained for four germplasms or cultivars at Chonnam National University, Gwangju, South Korea, in 2017. Horizontal and vertical error bars in the panels $(\mathbf{b}, \mathbf{c})$ represent \pm 1 SD of the corresponding mean values, and $\mathrm{r}$ is Pearson's correlation coefficient. 
The updated RSCM model for soybean also adopts the within-season calibration process to receive proximal or remote sensing data as an input whereby the simulated and observed LAIs are compared. The model employs parameters $\left(L_{0}, a, b\right.$, and $\left.c\right)$ to describe the soybean canopy growth processes. These parameter values are obtained using the Bayesian method based on a prior distribution chosen according to estimates of the seasonal LAI and VIs measured from previous studies (i.e., the parameterization dataset in the current study). VI is technically a two-dimensional estimation of the plant canopy, while LAI is a three-dimensional perception. Employing these different concepts, the relationships between LAI and the four VIs, labelled $\ell=1,2,3$, and 4 (Equations (1)-(4)), are formulated using log-log linear regression models. The description in detail is as follows. The regression model below is designed for each VI:

$$
\log \left(\mathrm{VI}_{\mathrm{t}}\right)=\alpha_{V I}+\beta_{V I} \log \left(L A I_{t}\right)+\epsilon_{t}
$$

where $\epsilon_{\mathrm{t}} \sim N\left(0, \sigma_{V I}^{2}\right)$. The RSCM-soybean model explains the evolution of LAI for each run using four parameters $\theta=\left(L_{0}, a, b\right.$, and $\left.c\right)$.

These parameters are assumed to be generated from the prior distribution $\psi \sim N(\mu, D)$, using the transformations as follows:

$$
\begin{gathered}
\psi=\left(\psi_{1}, \psi_{2}, \psi_{3}, \psi_{4}\right)=\left(\log \frac{a}{1-a}, \log \frac{b}{1-b}, \log \frac{c}{1-c}, \log \frac{L_{0}}{1-L_{0}}\right) \\
\theta=\theta(\psi)=\left(\frac{e^{\psi_{1}}}{1+e^{\psi_{1}}}, \frac{e^{\psi_{2}}}{1+e^{\psi_{2}}}, \frac{e^{\psi_{3}}}{1+e^{\psi_{3}}}, \frac{e^{\psi_{4}}}{1+e^{\psi_{4}}}\right)
\end{gathered}
$$

where $\psi$ and $\theta$ represent the transformation functions using a logarithmic equation and an exponential algebraic formula for the parameters. The procedures formulated above make all the four parameters $\left(L_{0}\right.$, $a, b$, and $c$ ) range between 0 and 1 . Both the regression coefficients $\left(\alpha_{\ell}, \beta_{\ell}\right.$, and $\sigma_{\ell}^{2}, \ell=1,2,3$, and 4$)$ and the hyper-parameters $(\mu, D)$ are obtained from data collected in the current studies for calibration and validation that include both measured LAIs and VIs. The parameter $\mu$ is identified using the default values (i.e., $L_{0}=0.2, a=3.25 \times 10^{-1}, b=1.25 \times 10^{-3}$, and $c=1.25 \times 10^{-3}$ ); parameter $\mathrm{D}$ is chosen as a diagonal matrix with all diagonal elements equal to 0.5 .

The following numerical procedure is employed to obtain the four parameters $(\theta)$ for each run. In Phase 1 , set $\mu$ as the initial estimation of $\psi$ for each run.

In Phase 2, define $\mathrm{LAI}_{\mathrm{t}}=\widetilde{\mathrm{G}}(t ; \psi)=G(t ; \theta(\psi))$ and design the following objective formula:

$$
\sum_{\ell=1}^{5}\left\{\frac{1}{\sigma_{\ell}^{2}} \sum_{t=1}^{n}\left(\log V I_{\ell t}-\alpha_{\ell}-\beta_{\ell} \log \widetilde{G}(t ; \psi)\right)^{2}\right\}+(\psi-\mu)^{\prime} D^{-1}(\psi-\mu)
$$

In Phase 3, generate the simulated curve for each run from the estimated $\psi$ in Phase 2.

In Phase 4, update $\mu, \mathrm{D}$ as the sample means and sample variances of the estimates in Phase 2.

In the procedure, the parameter $\psi$ is estimated by minimizing the above formula. Optimisation is achieved using the POWELL optimisation routine [34]. All the parameters are adequately reparametrized to cause agreement between simulation and observation owing to the optimisation (Table A1).

\subsection{Statistical Analysis}

In this study, four statistical indices were used to determine the crop parameters and evaluate the performance of the RSCM regime: Pearson's correlation coefficient (r), $p$ according to the two-sample 
t-test, root mean square error (RMSE), and Nash-Sutcliffe efficiency (NSE) [35]. The RMSE and NSE were determined using the following formulas:

$$
\begin{gathered}
\text { RMSE }=\sqrt{\frac{1}{n} \sum_{i=1}^{n}\left(S_{i}-M_{i}\right)^{2}} \\
\mathrm{NSE}=1-\frac{\sum_{i=1}^{n}\left(S_{i}-M_{i}\right)^{2}}{\sum_{i=1}^{n}\left(M_{i}-M_{\text {mean }}\right)^{2}}
\end{gathered}
$$

where $S_{i}$ is the ith simulated value, $M_{i}$ is the ith measured value, $M_{\text {mean }}$ is the mean measured value, and $\mathrm{n}$ is the total number of observations. NSE can range between $-\infty$ and one. The model performance is assessed to be dependable when the value is closer to one. If the value becomes less than zero, it means the model performance is less dependable.

\section{Results}

\subsection{Estimation of Crop Growth-specific Parameters}

The values of the three parameters of RUE, SLA, and light extinction coefficient $(\mathrm{k})$ were estimated based on the empirical relationships between the required crop growth variables that were determined from the field experiments in this study. The estimated mean RUE for the four soybean germplasms was $1.65 \mathrm{~g} \mathrm{MJ}^{-1}$ from the slope of the linear regression between above-ground biomass and cumulative intercepted PAR on the soybean canopy (Figure 2a). SLA for soybean was estimated as $0.017 \mathrm{~m}^{2} \mathrm{~g}^{-1}$ that was determined based on the regression line between leaf biomass weight and LAI (Figure $2 b$ ). The $\mathrm{k}$ value was determined as 0.71 (Figure 2c) based on the assumption of light interception in the soybean canopy according to Beer's law.

\subsection{Evaluation (Calibration and Validation) of RSCM}

Simulated (S) LAI and AGDM were in agreement with the corresponding measured (M) LAI and AGDM, with RMSE and NSE of $0.40 \mathrm{~m}^{2} \mathrm{~m}^{-2}$ and 0.86 in LAI and $155.5 \mathrm{~g} \mathrm{~m}^{-2}$ and 0.80 in AGDM, obtained in 2017 for calibrating the RSCM scheme based on an LAI input option (Figure 3). RMSE varied from 0.30 to $0.38 \mathrm{~m}^{2} \mathrm{~m}^{-2}$ in LAI and from 79.83 to $102.72 \mathrm{~g} \mathrm{~m}^{-2}$ in AGDM, while NSE showed a range of 0.85-0.93 in LAI and a range of 0.92-0.95 in AGDM for each germplasm or cultivar (Table A2). Likewise, SLAI and SAGDM were in agreement with the corresponding observed (O) LAI and AGDM, with RMSE and NSE of $0.69 \mathrm{~m}^{2} \mathrm{~m}^{-2}$ and 0.66 in LAI and of $166.9 \mathrm{~g} \mathrm{~m}^{-2}$ and 0.90 in AGDM, obtained in 2017 for calibrating RSCM based on a VI input option (Figure 4). RMSE ranged from 0.61 to 0.76 $\mathrm{m}^{2} \mathrm{~m}^{-2}$ in LAI and from 112.38 to $212.90 \mathrm{~g} \mathrm{~m}^{-2}$ in AGDM, while NSE showed a range of -0.40 to 0.37 in LAI and a range of $0.62-0.89$ in AGDM for each germplasm or cultivar (Table A2). There were no significant differences between simulated and measured yields for the LAI ( $p=0.31)$ or VI $(p=$ 0.54 ) input options according to two-sample t-tests (Figure 5). The simulated yields agreed with the measured yields with RMSEs of $336.5 \mathrm{~kg} \mathrm{ha}^{-1}$ for the LAI input option and of $625.6 \mathrm{~kg} \mathrm{ha}^{-1}$ for the VI input option. 

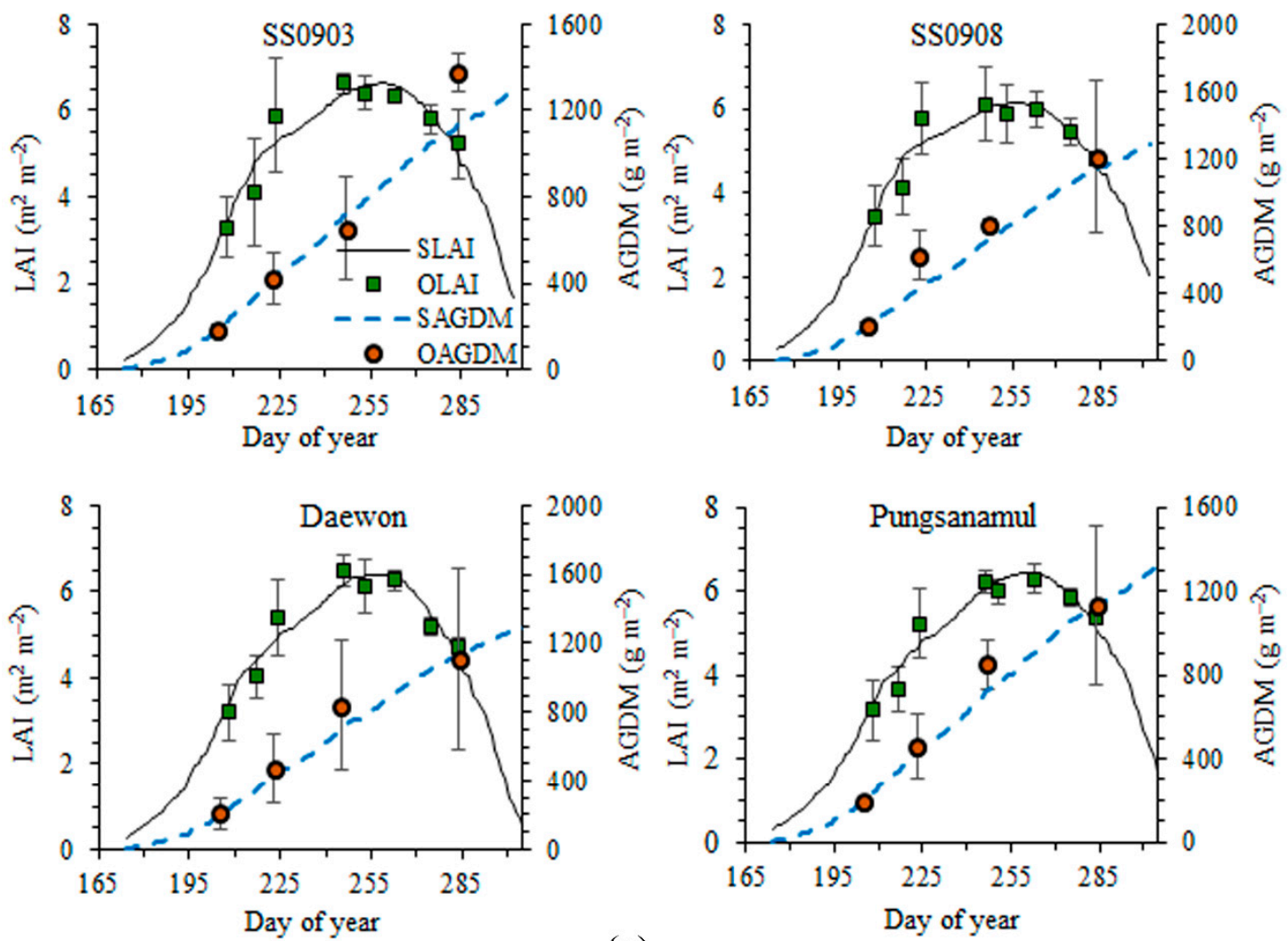

(a)
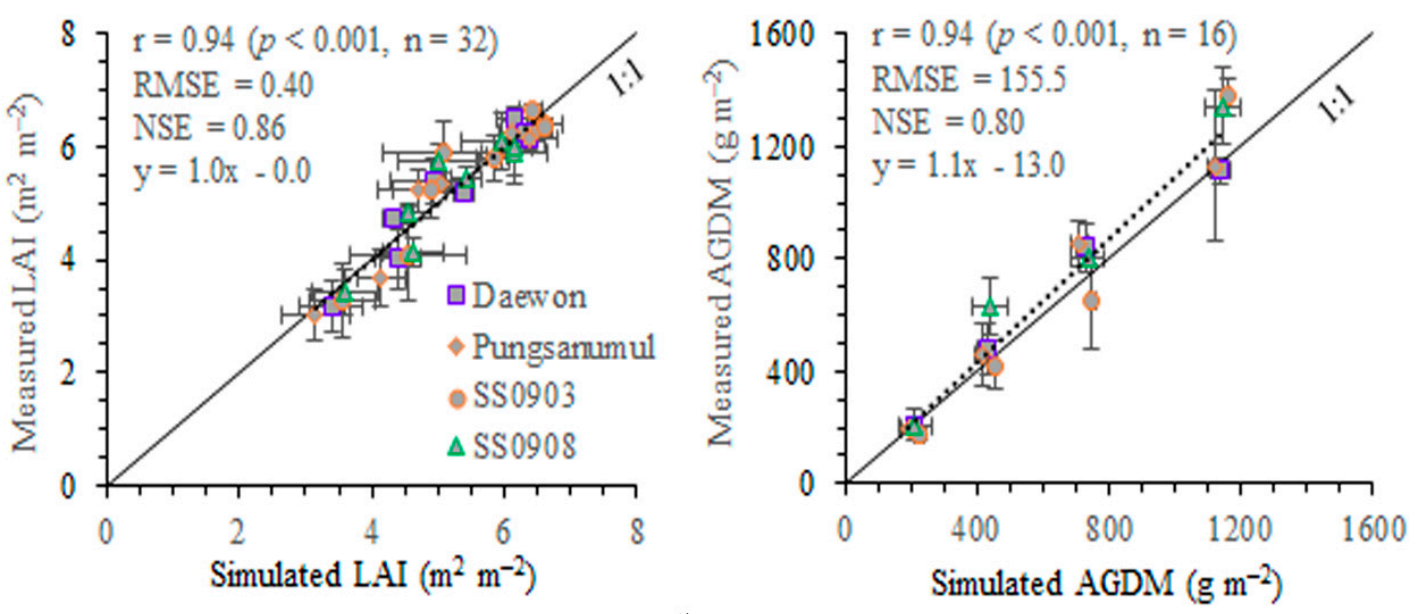

(b)

Figure 3. Model calibration: Simulated (S) and measured (M), observed (O) LAI and above-ground dry mass (AGDM) for four soybean germplasms or cultivars, SS0903, SS0908, Daewon, and Poongsanamul based on the leaf area index (LAI) input option (a) and comparisons between $\mathrm{S}$ and $\mathrm{M}$ values for LAI and AGDM (b). Data were obtained at Chonnam National University, Gwangju, South Korea, in 2017. Vertical and horizontal error bars represent the standard deviations \pm 1 SD of the mean values. The solid and dotted lines in the panel (b) represent the ratio 1:1 and a linear fit, respectively. NSE, RMSE, and $r$ denote Nash-Sutcliffe efficiency, root mean square error, and Pearson's correlation coefficient, respectively. 

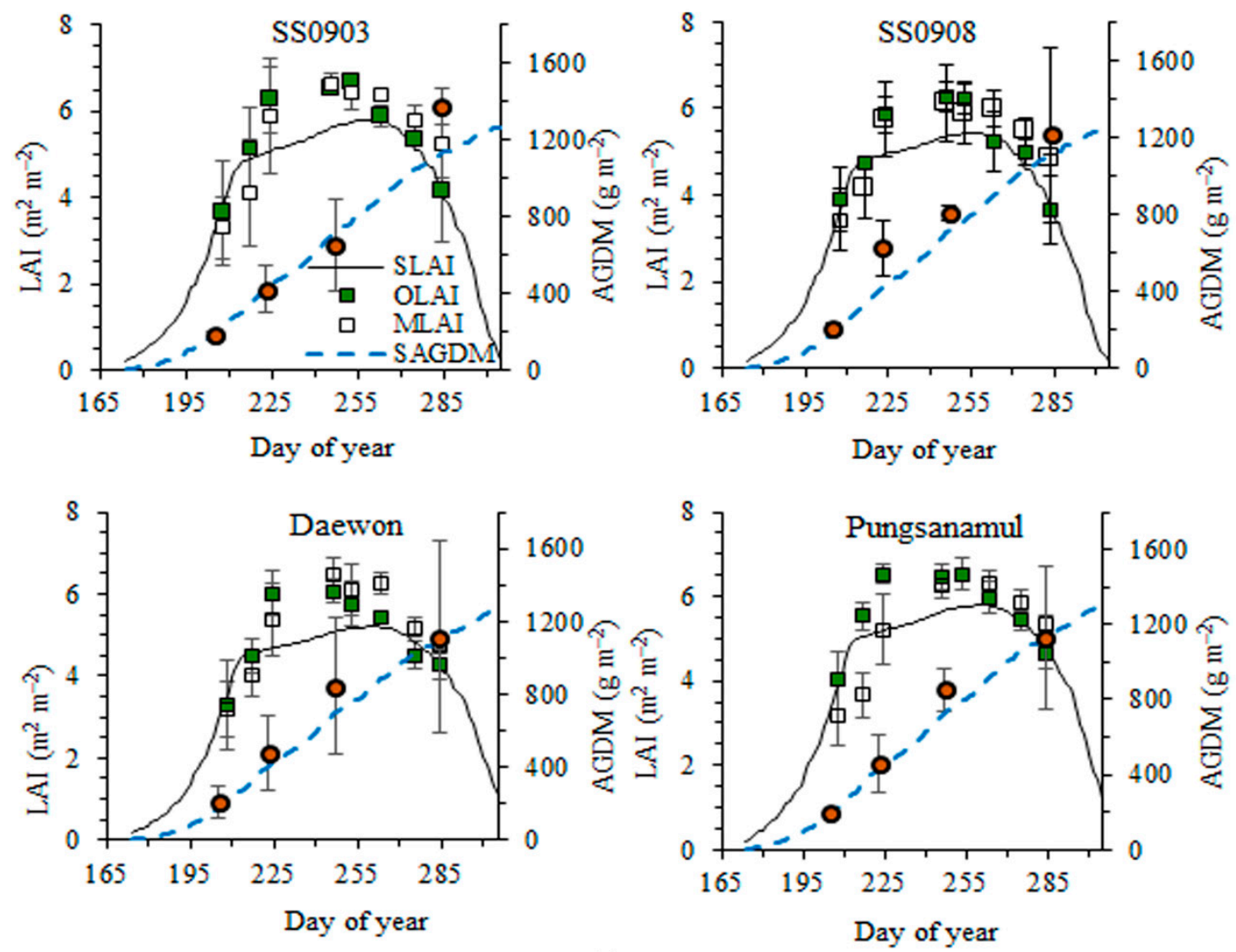

(a)
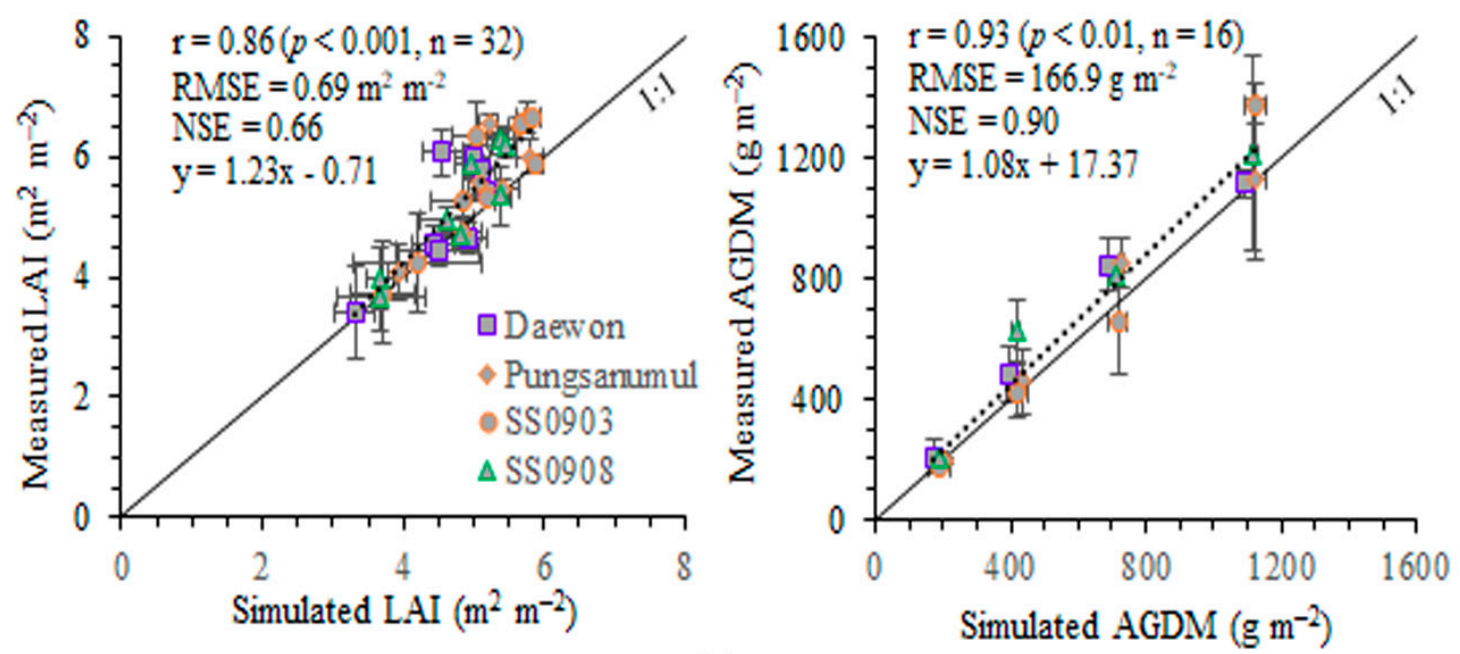

(b)

Figure 4. Model calibration: Simulated (S) and measured (M), observed (O) LAI and above-ground dry mass (AGDM) for four soybean germplasms or cultivars, SS0903, SS0908, Daewon, and Poongsanamul based on the vegetation index input option (a), and comparisons between $\mathrm{S}$ and $\mathrm{M}$ values for LAI and AGDM (b). Data were obtained at Chonnam National University, Gwangju, South Korea in 2017. Vertical and horizontal error bars represent the standard deviations \pm 1 SD of the mean values. The solid and dotted lines in the panel (b) represent the ratio 1:1 and a linear fit, respectively. NSE, RMSE, and $r$ denote Nash-Sutcliffe efficiency, root mean square error, and Pearson's correlation coefficient, respectively. 


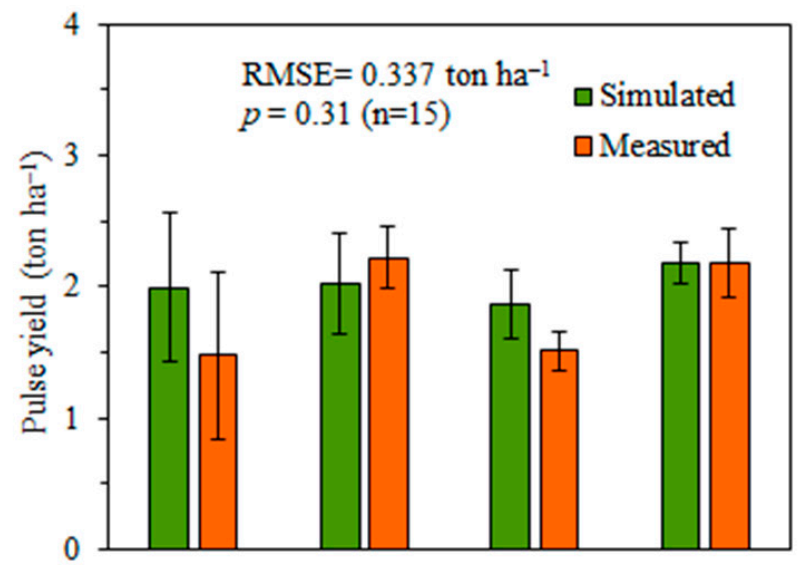

(a)

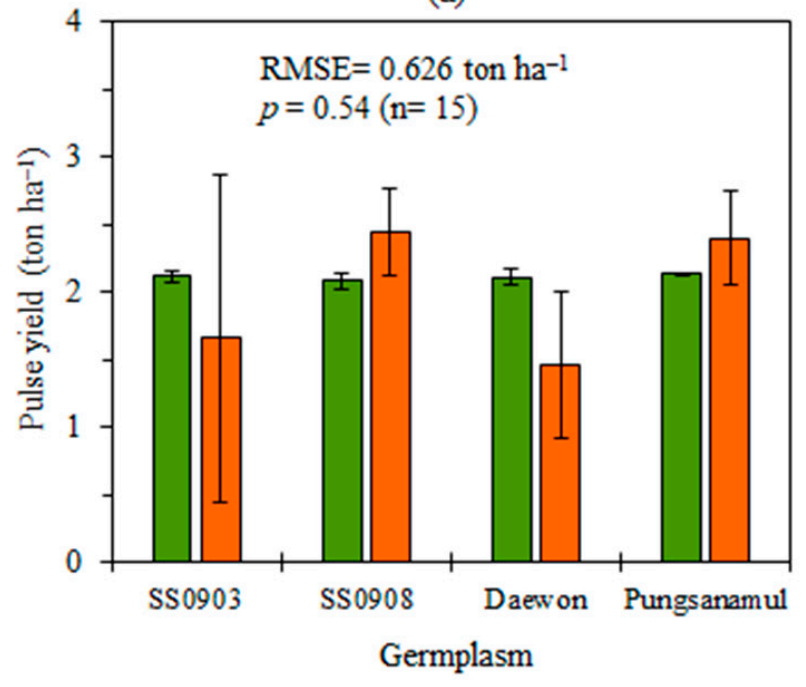

(b)

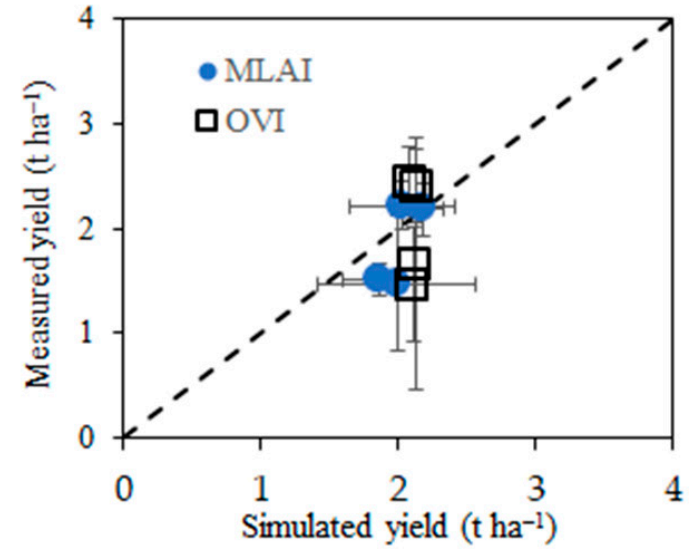

(c)

Figure 5. Comparisons between simulated and measured soybean pulse using different input options, measured leaf area index (MLAI) (a) and observed vegetation indices (OVI) based on proximal sensing (b), at Chonnam National University, showing those for both options (c) Gwangju, South Korea in 2017. Vertical error bars represent \pm 1 SE of the mean values. RMSE and $p$ denote root mean square error and the $p$ value according to the two-sample $t$-test.

SLAI and SAGDM agreed with the corresponding MLAI and MAGDM, with RMSE and NSE of $0.6 \mathrm{~m}^{2} \mathrm{~m}^{-2}$ and 0.89 in LAI and of $84.6 \mathrm{~g} \mathrm{~m}^{-2}$ and 0.96 in AGDM, obtained in 2018 for validating RSCM based on an LAI input option (Figure 6). RMSE varied from 0.37 to $0.83 \mathrm{~m}^{2} \mathrm{~m}^{-2}$ in LAI and from 39.25 to $101.49 \mathrm{~g} \mathrm{~m}^{-2}$ in AGDM, while NSE showed a range of 0.77-0.96 in LAI and a range of 0.94-0.99 in AGDM for each cultivar (Table A3). Likewise in the calibration, SLAI and SAGDM agreed reasonably well with the corresponding OLAI and MAGDM, with RMSE and NSE of $0.83 \mathrm{~m}^{2} \mathrm{~m}^{-2}$ and 0.92 in LAI and $74.9 \mathrm{~g} \mathrm{~m}^{-2}$ and 0.92 in AGDM, obtained in 2018 for validating RSCM based on a VI input option (Figure 7). RMSE ranged from 0.73 to $0.94 \mathrm{~m}^{2} \mathrm{~m}^{-2}$ in LAI and from 43.10 to $105.54 \mathrm{~g}$ $\mathrm{m}^{-2}$ in AGDM, while NSE had a range of 0.56-0.74 in LAI and a range of 0.93-0.99 in AGDM for each cultivar (Table A3). There was no significant difference between simulated and measured yields for both the LAI $(p=0.31)$ and VI $(p=0.92)$ input options according to two-sample t-tests (Figure 8$)$. The simulated yields agreed with the measured yields, with RMSEs of 0.652 ton ha ${ }^{-1}$ for the LAI input option and of 0.508 ton $\mathrm{ha}^{-1}$ for the VI input option. 

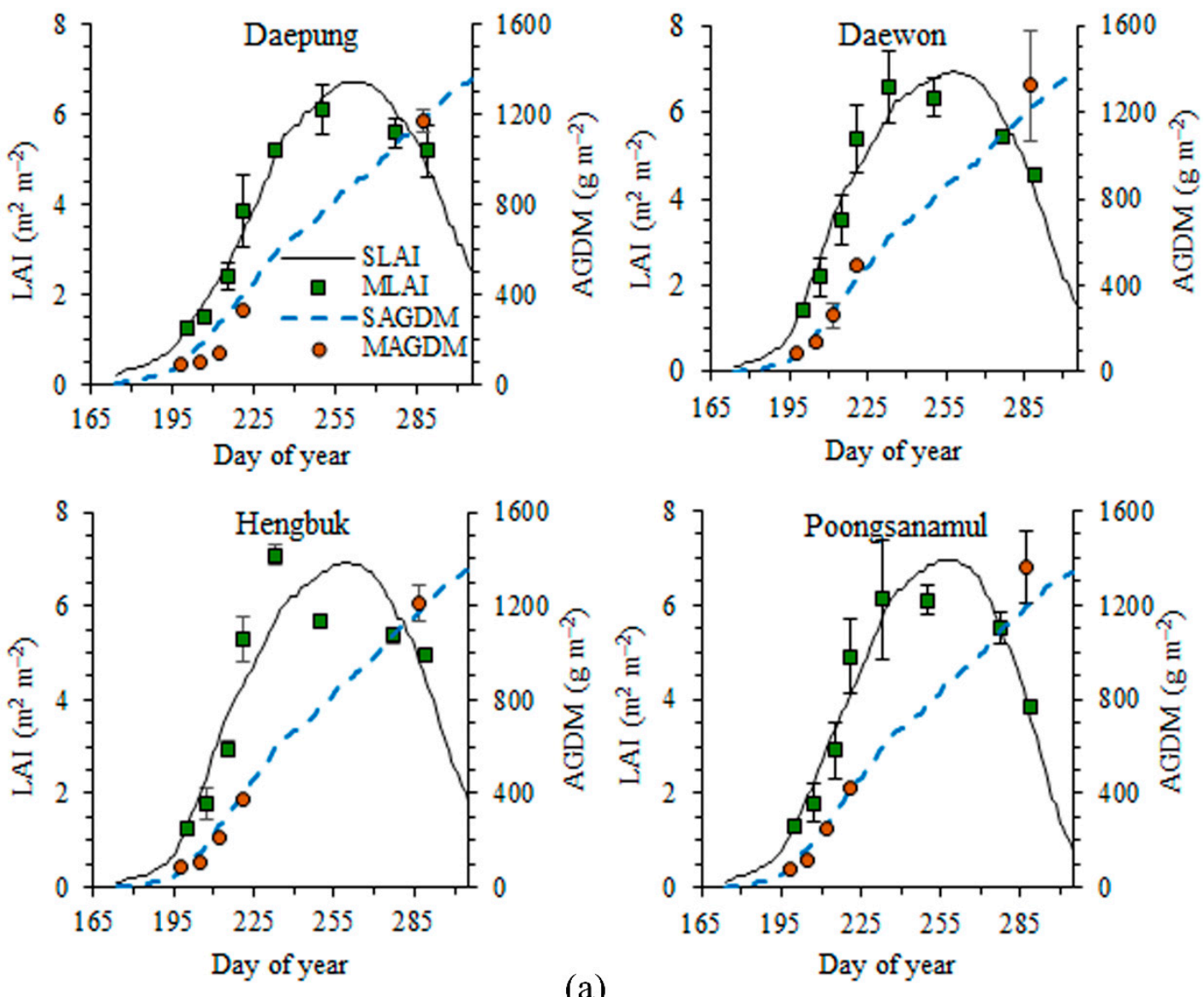

(a)
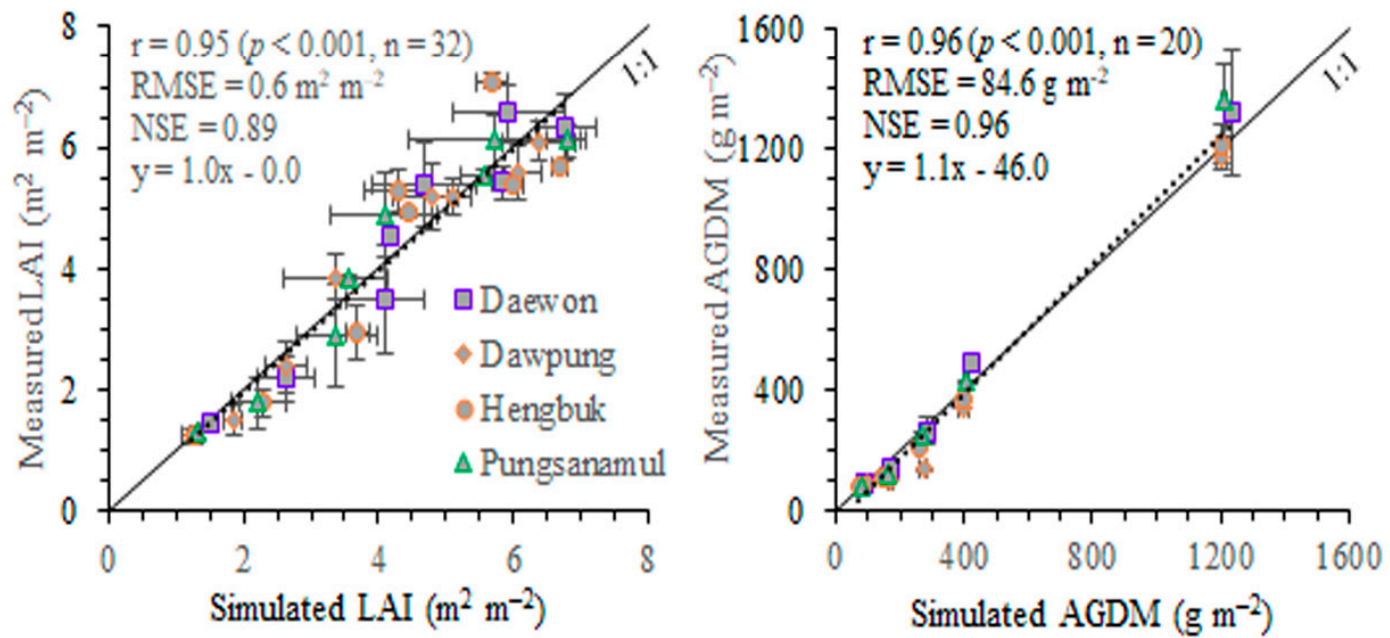

(b)

Figure 6. Model validation: Simulated (S) and measured (M), observed (O) values in LAI and S and M values in above-ground dry mass (AGDM) for four soybean cultivars, Daepung, Daewon, Hengbuk, and Poongsan based on the leaf area index (LAI) input option (a) and comparisons between S and M values in LAI and AGDM (b). Data were obtained at Chonnam National University, Gwangju, South Korea, in 2018. Vertical and horizontal error bars represent \pm 1 SD of the means values. The solid and dotted lines in the panel (b) represent the ratio 1:1 and a linear fit, respectively. NSE, RMSE, and r denote Nash-Sutcliffe efficiency, root mean square error, and Pearson's correlation coefficient, respectively. 

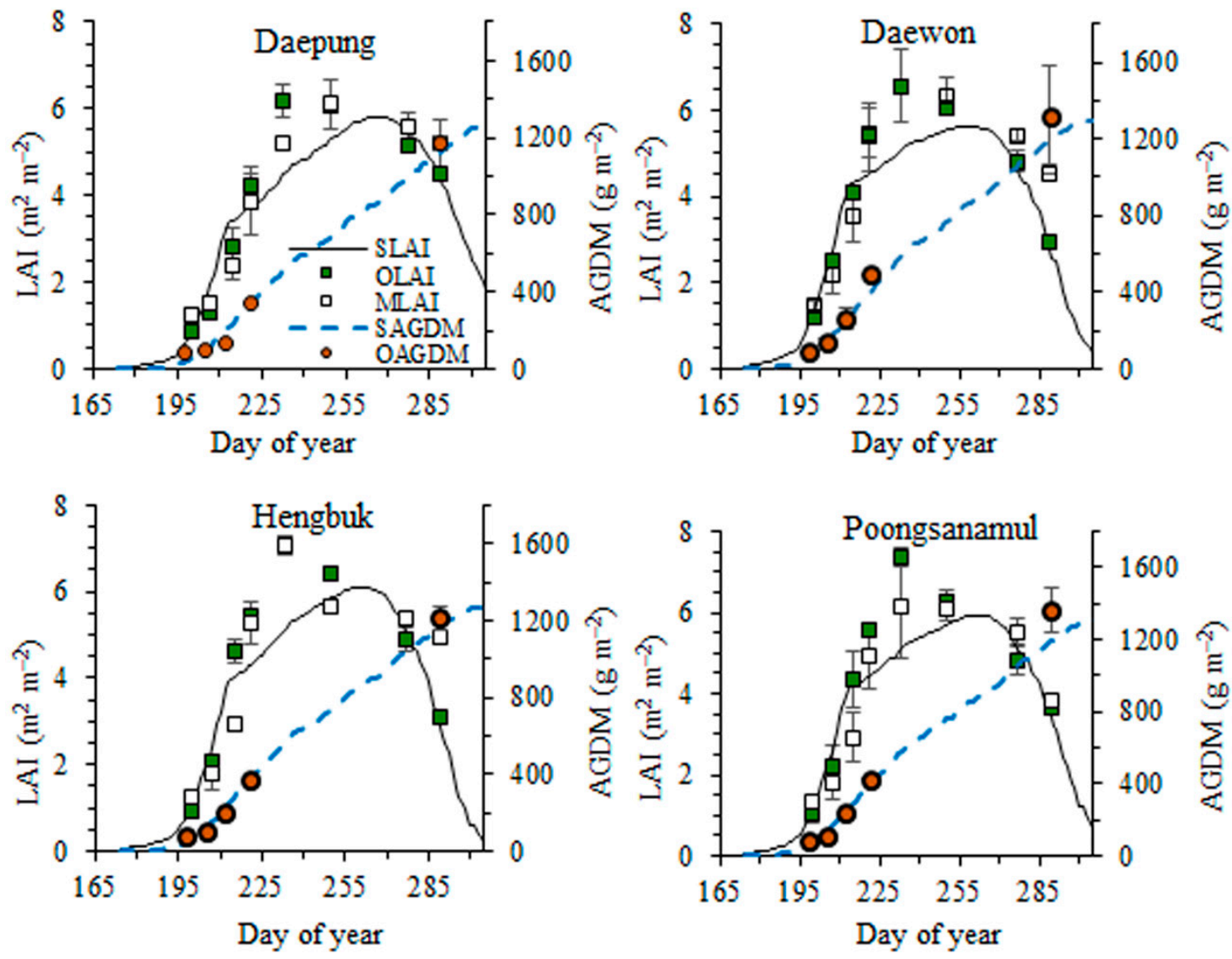

(a)
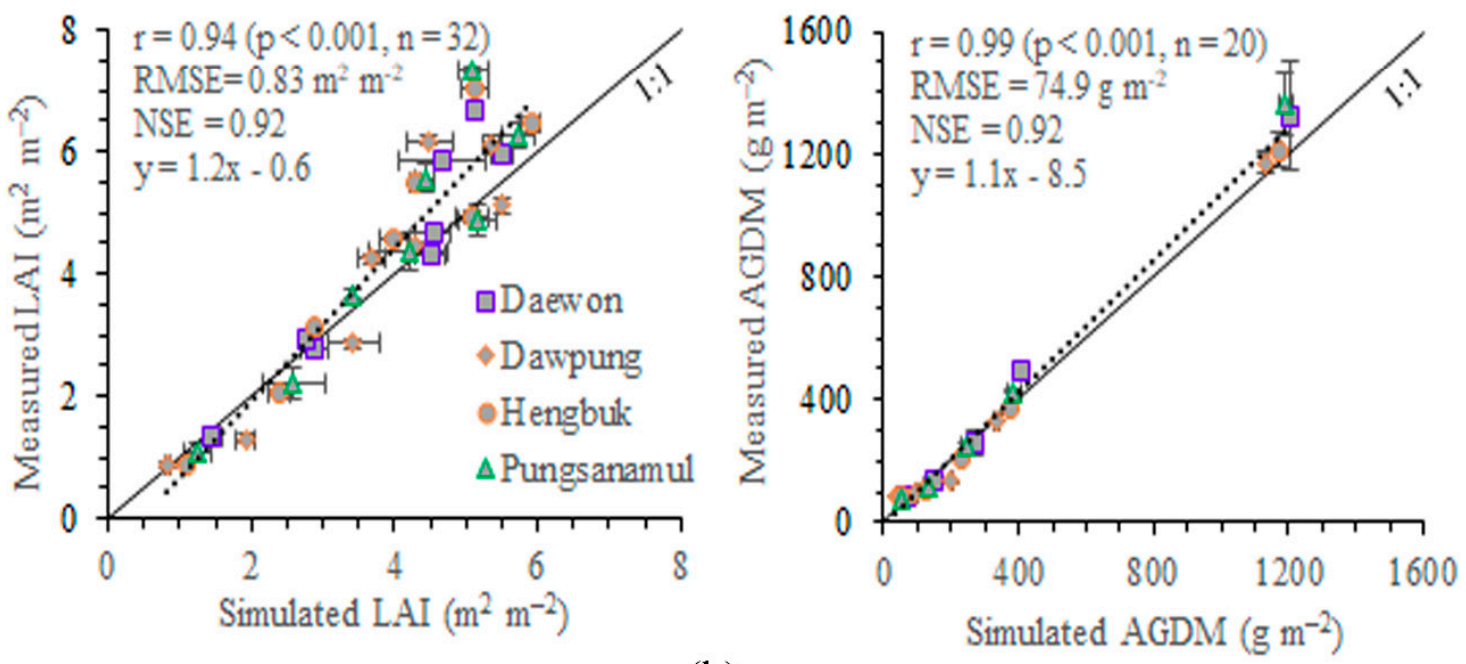

(b)

Figure 7. Model validation: Simulated $(\mathrm{S})$ and measured $(\mathrm{M})$, observed $(\mathrm{O})$ values in LAI and $\mathrm{S}$ and $\mathrm{M}$ values in above-ground dry mass (AGDM) for four soybean cultivars, Daepung, Daewon, Hengbuk, and Poongsan based on the VI input option (a) and comparisons between S and M values in LAI and AGDM (b). Data were obtained at Chonnam National University, Gwangju, South Korea in 2018. Vertical and horizontal error bars represent \pm 1 SD of the means values. The solid and dotted lines in the panel (b) represent the ratio 1:1 and a linear fit, respectively. NSE, RMSE, and r denote Nash-Sutcliffe efficiency, root mean square error, and Pearson's correlation coefficient, respectively. 


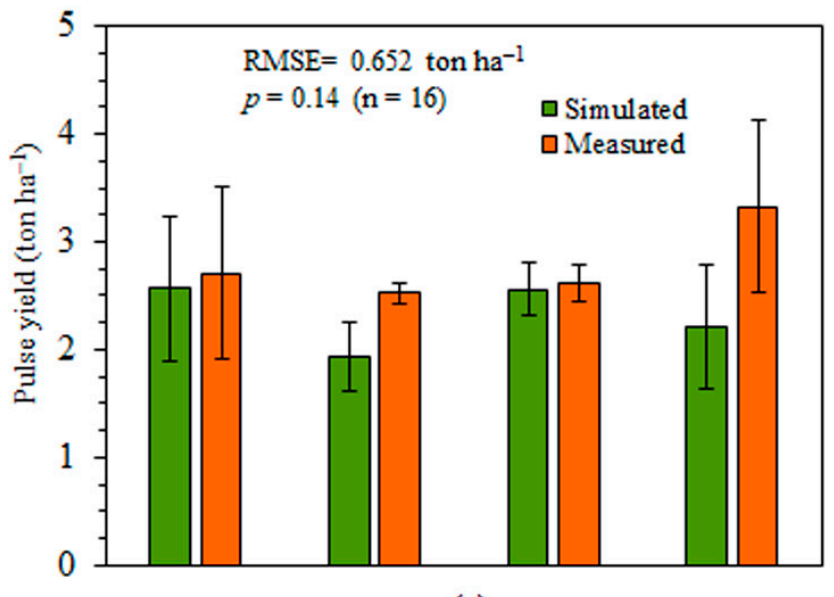

(a)

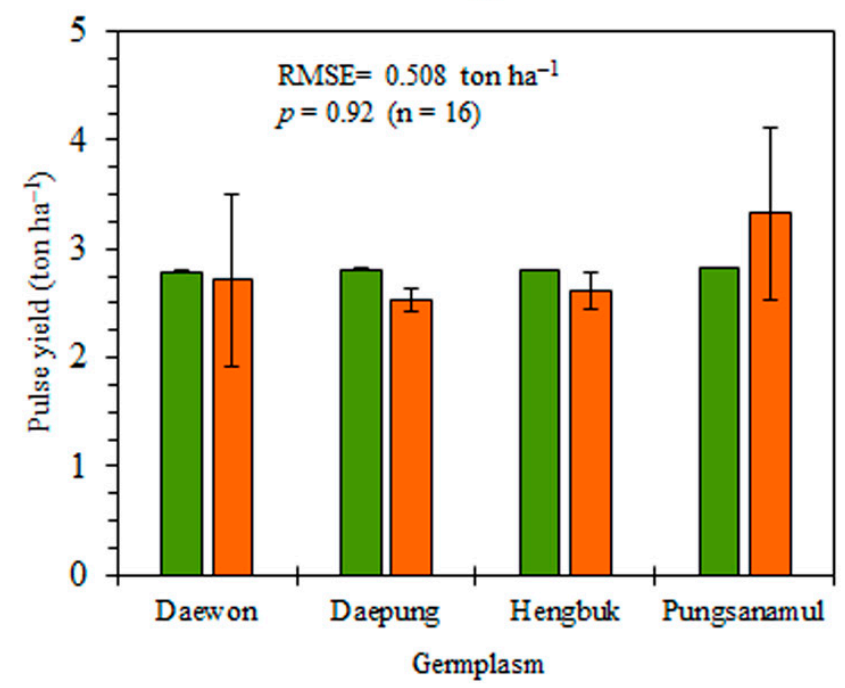

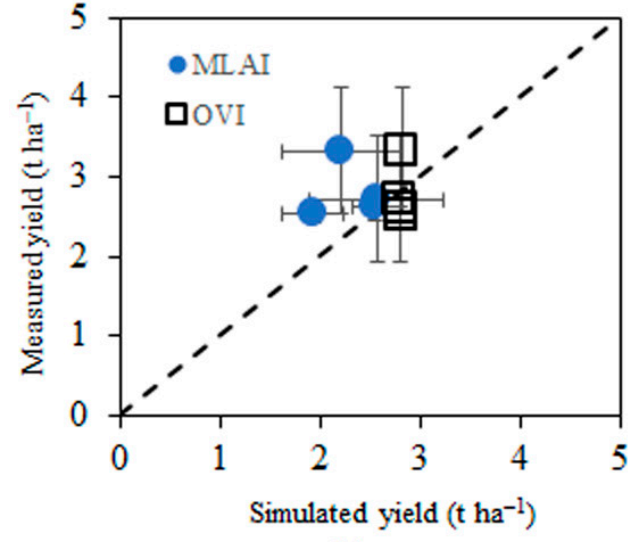

(c)

(b)

Figure 8. Comparisons between simulated and measured soybean pulse yields using different input options, measured leaf area index (MLAI) (a), and observed vegetation indices (OVI) based on proximal sensing (b), showing those for both options (c) at Chonnam National University, Gwangju, South Korea in 2018. Vertical and horizontal error bars represent \pm 1 SE of the mean values. RMSE and $p$ denote root mean square error and the $p$ value according to the two-sample $t$-test.

In additional validation using a dataset obtained in 2017 at a separate site from the model calibration, SLAI agreed with the corresponding MLAI with RMSE and NSE of $1.2 \mathrm{~m}^{2} \mathrm{~m}^{-2}$ and 0.69 , in which RSCM simulation was carried out based on an LAI input option (Figure 9a). RMSE and NSE for each cultivar ranged from 0.93 to $1.47 \mathrm{~m}^{2} \mathrm{~m}^{-2}$ and from 0.45 to 0.80 , respectively (Table A4). There was no significant difference between simulated and measured yields $(p=0.58)$ according to a two-sample t-test (Figure 9b). The simulated yields agreed with the measured yields, with an RMSE of $596.3 \mathrm{~kg} \mathrm{ha}^{-1}$. 

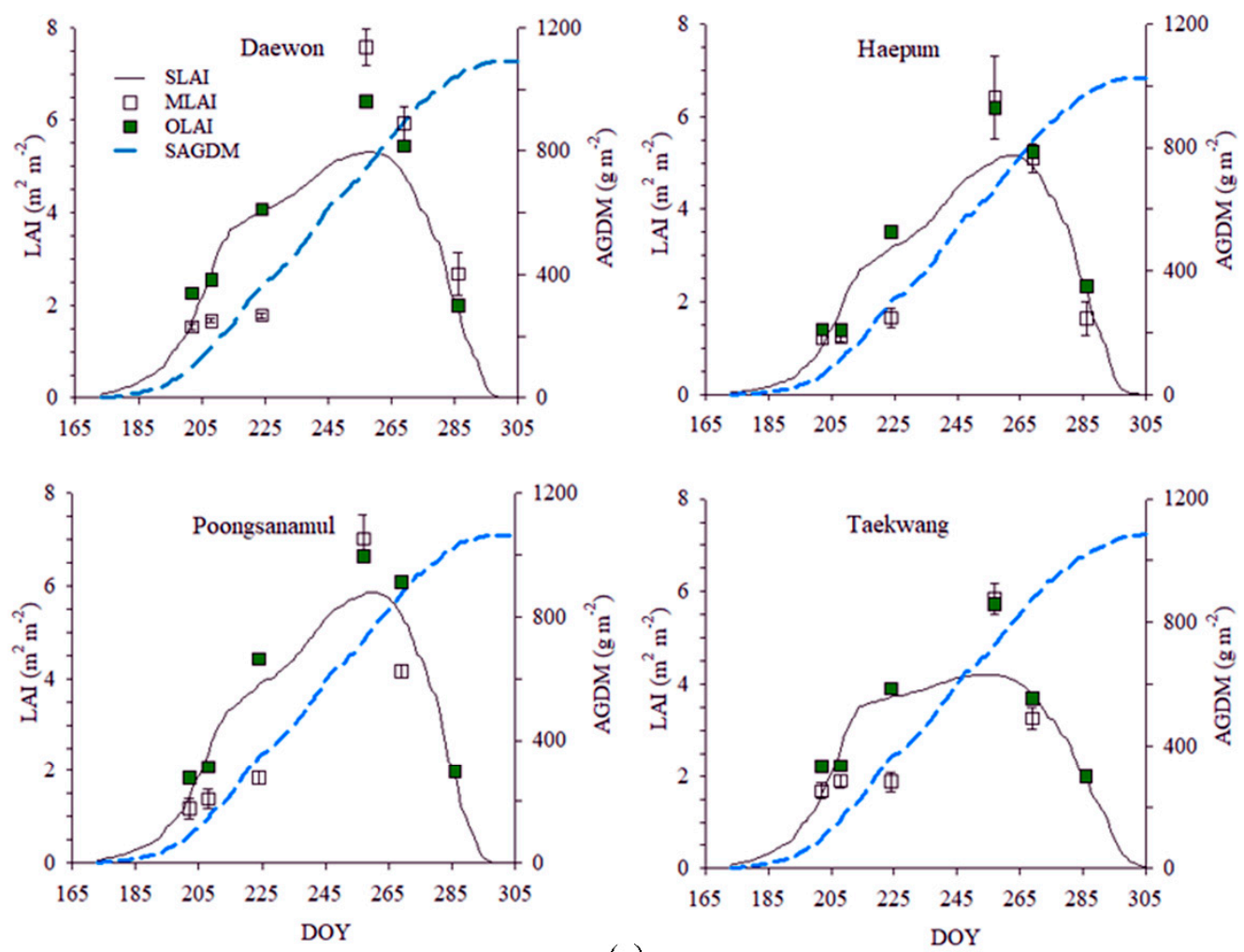

(a)

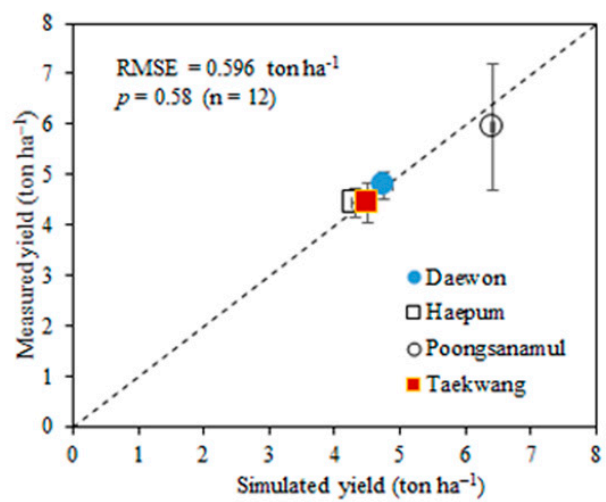

(b)

Figure 9. Model validation: Simulated $(\mathrm{S})$ and observed $(\mathrm{O})$, measured $(\mathrm{M})$ values in leaf area index (LAI) and $\mathrm{S}$ values in above ground dry mass (AGDM) for four soybean cultivars, Daewon, Haepum, Poongsanamul, and Taekwang (a), and comparisons between $S$ and $M$ values in soybean yield (b) for model validation. The data set was obtained at Jeonnam Agricultural Research and Extension Services in Naju, Chonnam province, South Korea in 2017. Vertical and horizontal error bars represent the standard deviations of the means values. RMSE and $p$ denote root mean square error and the $p$ value according to the two-sample $t$-test.

\section{Discussion}

The current study results demonstrated that the RSCM-soybean regime integrated with ground-based proximal sensing data was successfully calibrated and validated, which was performed according to the experimental estimation of the crop growth-specific parameters of RUE, SLA, and $\mathrm{k}$. We hereby discuss the appropriateness of the estimated parameter values in association with earlier reports by other researchers below. Discussion on the model evaluation process follows that on the experimental parameterisation. 
RUE is a crucial crop growth-specific parameter that is broadly used in crop growth models to understand the physiological aspects of crop canopy responses to cumulative intercepted PAR. Wilson [36] reported RUE as a constant for specific crop growth during the demonstration of a relationship between crop growth rate and solar radiation interception. Later, Monteith [32] stated a linear correlation between biomass partitioning upon harvested solar radiation and defined the slope as RUE. Variations in RUE have been observed due to biomass sampling methodologies and growth stages, either sampled on whole biomass or above-ground biomass basis; the use of solar radiation or the portion of solar radiation responsible for photosynthesis; errors during biomass sampling; non-uniform sample size or plots; leaf chlorophyll content; and water and nutrient status of the field [37]. Several meteorological factors are reported to show some effects on RUE, such as air temperature, and vapour pressure deficit [38]. The RUE value of $1.65 \mathrm{~g} \mathrm{MJ}^{-1}$ estimated in the current study agrees to the value reported by Liu et al. [39] who found an RUE range of 1.48-2.29 $\mathrm{g} \mathrm{MJ}^{-1}$ for soybean cultivated as an intercrop and monoculture with a population density of $14.2 \mathrm{~m}^{-2}$.

Accurate simulation of leaf area is crucial for the estimating intercepted solar radiation above a canopy and partitioning of biomass utilizing the light. Partitioning of new leaves is closely related to biomass accumulation in all growth stages. A typical lag phase is observed at the beginning of growth, followed by exponential growth later. SLA is an important parameter related to canopy expansion and biomass accumulation in crop models and is defined as the ratio between one leaf area and leaf blade dry matter accumulation by assimilating PAR [40]. SLA is crucial as an index of leaf nitrogen content, water content, leaf gas exchange, and canopy stress caused by abiotic or biotic factors and growth strategy [41]. High SLA indicates a high concentration of nitrogen, a high rate of $\mathrm{CO}_{2}$ assimilation, and high nitrogen uptake per unit leaf area. The SLA value of $0.017 \mathrm{~m}^{2} \mathrm{~g}^{-1}$ estimated in the current study was slightly smaller than the reported SLA range of 0.0179 to $0.0366 \mathrm{~m}^{2} \mathrm{~g}^{-1}$ for several soybean genotypes by Vile et al. [42]. SLA can vary with the locations of the leaves on a plant, the developmental phase of a leaf, leaf insertion, plant density, radiation intercepted, genotype, soil nutrient and fertilizer management, and the acting environment [43].

The light extinction coefficient $k$ is a crop growth specific parameter that controls the interception of solar radiation in the plant canopy. It varied in different phenological groups of the same crop and may differ within different cultivars and species [44]. According to Carpenter and Board [45], soybean has an intricate growth pattern with random distributions of nodes, branches, and leaves; after flowering stage, it can still produce new leaves, commonly known as indeterminate growth. The coefficient also depends on canopy leaf display and apex leaf angle with respect to the vertical position. Smaller parameter values indicate that much radiation can reach all leaves, while larger values indicate the opposite. Most crop modellers estimated $\mathrm{k}$ from transmitted and incoming PAR based on Beer's law [46]. Coefficient $\mathrm{k}$ was estimated using different techniques and devices, and we also did not practice at the same place or time. Therefore, $\mathrm{k}$ may also not be similar within the same crop. More light can be intercepted owing to the exponential growth of leaf area during the vegetative growth period. The estimated $k$ value of 0.71 is slightly higher than the $k$ range reported by Ebadi et al. [47] for different soybean cultivars. However, it agrees with the $\mathrm{k}$ range for the plants with horizontal leaves theorized by Rosenberg et al. [48].

We demonstrated above that the current determined parameters fit in a reasonable range within the study site of interest. These crop-specific parameters were well estimated based on the field experiment in this study. While these parameters are measurable, it is labour-intensive to obtain the values. As it was discussed above, these parameters can vary depending on different environments and genetic traits of soybean. The parameters can affect each other as well, for example, a decreased RUE from 1.75 to $1.5 \mathrm{~g} \mathrm{MJ}^{-1}$ to increase the light extinction coefficient from 0.3 to 1 , according to Bell et al. [49]. The scientific concept that we employed was that soybean growth could be calibrated for a given environment according to proximal sensing information using non-measurable but adjustable parameters employing the within-season calibration [18,50]. The non-measurable calibrated parameters include $a, b$, and $c$ for which $a$ and $b$ control the magnitude and shapes of an LAI curve up to the 
maximum LAI, while c controls the reduced amount of LAI at the senescence stage. These parameters are calibrated based on the within-season calibration procedure adopted in the current model. We discuss the implications of our model calibration results as well as some cons and pros of the within season-calibration procedure in the following paragraphs.

Achieving the desired simulated results in comparison with the measured ones by means of trial and error is termed model calibration [51]. Calibration is the most common technique in any model to get the best fit by adjusting initial model conditions and other model parameters in their recommended ranges through the observation between simulated and measured results $[4,18,52]$. We assume that a crop model is well calibrated when it reproduces the results resembling the actual condition. The RSCM model was well calibrated with statistically acceptable agreements between simulation and measurement or observation (see Figures 3 and 4 using the dataset employed for the estimated crop growth specific parameters as the model inputs (see Figure 2). Our model validation consequence also showed that RSCM-soybean could reproduce soybean growth, development, and yield with reasonable accuracies (Figures 5-7). We demonstrated that RS information could be well integrated into the model to simulate soybean using simple input requirements. In addition, the simulated yields for the VI input option were not significantly different from the measured yields, meaning that proximal or remote sensing might be potentially substituted in some instances [53]. While there was an earlier report on a simulation of soybean using RSCM (previously GRAMI) [19], the current report is the first one carried out according to the experimental parameterisation using the updated RSCM regime [5].

These evaluation study outcomes of the RSCM regime indicated that the within-season calibration was effective with both observed and remotely sensed data integrated into the model. The extended RSCM-soybean model hypothetically adopts a Bayesian approach to calibrate the parameter values that control leaf partitioning and senescence to make simulation and observation results concurrent based on POWELL optimisation [34], as it is described in the earlier section. The adopted parameter estimation approach is theoretically characteristic and helpful for integrating different proximal or remote sensing data into the model that strongly depends on observed or remotely sensed information. The three distinct advantages owing to the stable incorporation of RSCM with proximal or remote sensing data are as follows. Firstly, the methodology requires simple input; this approach allows utilising the present observations that specify the environmental conditions (e.g., soil properties and micrometeorological factors), as with the earlier versions of RSCM [5,20,21]. Secondly, optimising the model improves simulation performance. Last, RSCM can be integrated with proximal or remote sensing data from different platforms, for example, an unmanned aerial system [54] and operational optical satellites $[14,15,55]$. Meanwhile, RSCM has some limitations, such as the strong dependence on proximal or remote sensing data as well as the inapplicability of reproducing the effects of photoperiod and phenology, $\mathrm{N}$ fixation, and $\mathrm{N}$ dynamics in comparison with other conventional process-based crop models. It is significant to secure solid analytical schemes to obtain accurate RS information on the study site of interest as inadequate RS data and partial observations can result in some disagreement between simulation and measurement or observation. Further studies need to be performed in various environmental conditions for future application. It would add significant value if the model could forecast crop growth and yield.

\section{Conclusions}

In this study, we determined soybean growth-specific parameters of RUE, SLA, and k based on field experiments, which were verified to be adequate for the study region. The RSCM soybean regime showed efficient simulation performances in both calibration and validation. Simulated LAI and AGDM values considerably well agreed with the measured values. The RSCM also reproduced soybean yields in agreement with the measured yields in the model assessment. We assume that a well-calibrated crop model can be effectively applied to different simulation projects with various environments and scenarios for the crop of interest. We also demonstrated that the RS data were well integrated into the soybean modelling design, meaning that the RSCM-soybean scheme can be 
well implemented to soybean monitoring projects for regions of interest where RS information can be obtained. RSCM-soybean is easy to use and applicable to many areas, requiring simple input parameters and variables owing to the optimization procedure of the model using RS data as an input option.

Author Contributions: Conceptualization, J.K., B.H., D.K.K., and H.-Y.K.; methodology, B.H., D.K.K., and H.-Y.K.; software, J.K.; validation, formal analysis, and investigation, A.R.S.; resources and data curation, S.J.; writing-original draft preparation, A.R.S. and J.K.; writing-review and editing, J.K.; visualization, A.R.S.; supervision, J.K.; project administration, S.J.; funding acquisition, J.K. All authors have read and agreed to the published version of the manuscript.

Funding: This research was supported by "Cooperative Research Program for Agriculture Science \& Technology Development (Project No. PJ013841022018)" from Rural Development Administration, Republic of Korea. Partial support was made by the Basic Science Research Program through the National Research Foundation of Korea (NRF), funded by the Ministry of Education, Science, and Technology (NRF-2018R1D1A1B07042925).

Conflicts of Interest: The authors declare no conflict of interest. The funders had no role in the design of the study; in the collection, analyses, or interpretation of data; in the writing of the manuscript, or in the decision to publish the results.

\section{Appendix A}

Table A1. Converged parameters of initial leaf area index $\left(\mathrm{L}_{0}\right)$ and leaf partitioning and senescence (a, $b$, and c) after the within-season calibration of the RSCM regime for germplasms or cultivars of soybean used in 2017 and 2018 at Chonnam National University (CNU), Gwangju and in 2017 at Jeonnam Agricultural Research and Extension Services (JARES) in Naju, Chonnam province, South Korea.

\begin{tabular}{ccccccc}
\hline Site & Year & Germplasm & $\mathbf{L}_{\mathbf{0}}$ & $\mathbf{a}$ & $\mathbf{b}$ & $\mathbf{c}$ \\
\hline CNU & 2017 & SS0903 & 0.166 & 0.001 & 0.005 & 0.004 \\
& & SS0908 & 0.158 & 0.001 & 0.005 & 0.003 \\
& Daewon & 0.124 & 0.001 & 0.004 & 0.002 \\
& & Poongsanamul & 0.186 & 0.001 & 0.004 & 0.002 \\
\hline \multirow{2}{*}{2018} & Daepung & 0.022 & 0.001 & 0.004 & 0.007 \\
& & Daewon & 0.047 & 0.001 & 0.005 & 0.003 \\
& & Hengbuk & 0.032 & 0.001 & 0.004 & 0.007 \\
\hline \multirow{2}{*}{2017} & Daewon & 0.065 & 0.001 & 0.005 & 0.007 \\
& & Haepum & 0.032 & 0.001 & 0.005 & 0.011 \\
& & Poongsanamul & 0.050 & 0.001 & 0.005 & 0.010 \\
& & Taekwang & 0.060 & 0.001 & 0.005 & 0.003 \\
\hline
\end{tabular}

Table A2. Error statistics of root mean square (RMSE) and Nash-Sutcliffe efficiency (NSE) in comparison between simulation (S) and observation (O) of leaf area index (LAI) and above ground dry mass (AGDM) for soybean germplasms or cultivars, simulated with different input options (i.e., LAI or VI) for the RSCM regime using the data obtained at Chonnam National University, Gwangju, South Korea in 2017.

\begin{tabular}{|c|c|c|c|c|c|c|c|c|c|}
\hline \multirow{3}{*}{ Option } & \multirow{3}{*}{ Germplasm } & \multicolumn{4}{|c|}{ LAI } & \multicolumn{4}{|c|}{ AGDM } \\
\hline & & $\mathrm{S}$ & $\mathrm{O}$ & RMSE & NSE & $\mathrm{S}$ & $\mathrm{O}$ & RMSE & NSE \\
\hline & & \multicolumn{3}{|c|}{$\mathrm{m}^{2} \mathrm{~m}^{-2}$} & n/a & \multicolumn{3}{|c|}{$\mathrm{g} \mathrm{m}^{-2}$} & n/a \\
\hline \multirow[t]{4}{*}{ LAI } & SS0903 & 5.47 & 5.46 & 0.38 & 0.88 & 634.5 & 656.5 & 97.23 & 0.95 \\
\hline & SS0908 & 5.21 & 5.20 & 0.34 & 0.85 & 647.6 & 713.6 & 102.72 & 0.92 \\
\hline & Daewon & 5.17 & 5.17 & 0.31 & 0.92 & 636.6 & 659.5 & 88.22 & 0.93 \\
\hline & Poongsanamul & 5.23 & 5.22 & 0.30 & 0.93 & 643.6 & 664.9 & 79.83 & 0.95 \\
\hline \multirow[t]{4}{*}{$\mathrm{VI}^{\delta}$} & SS0903 & 5.05 & 5.49 & 0.68 & 0.37 & 611.7 & 656.5 & 167.08 & 0.77 \\
\hline & SS0908 & 4.74 & 5.13 & 0.61 & 0.32 & 610.2 & 713.6 & 212.90 & 0.62 \\
\hline & Daewon & 4.63 & 5.03 & 0.76 & -0.40 & 586.7 & 659.5 & 112.38 & 0.89 \\
\hline & Poongsanamul & 5.21 & 5.69 & 0.69 & -0.26 & 621.9 & 658.3 & 159.71 & 0.78 \\
\hline
\end{tabular}


Table A3. Error statistics of root mean square (RMSE) and Nash-Sutcliffe efficiency (NSE) in comparison between simulated $(\mathrm{S})$ and observed $(\mathrm{O})$ of leaf area index (LAI) and above ground dry mass (AGDM) for soybean germplasms or cultivars, simulated with different input options (i.e., LAI or VI) for the RSCM regime using the data obtained at Chonnam National University, Gwangju, South Korea in 2018.

\begin{tabular}{|c|c|c|c|c|c|c|c|c|c|}
\hline \multirow{3}{*}{ Option } & \multirow{3}{*}{ Germplasm } & \multicolumn{4}{|c|}{ LAI } & \multicolumn{4}{|c|}{ AGDM } \\
\hline & & $S$ & $\mathrm{O}$ & RMSE & NSE & S & $\mathrm{O}$ & RMSE & NSE \\
\hline & & \multicolumn{3}{|c|}{$-m^{2} m^{-2}$} & $\mathrm{n} / \mathrm{a}$ & \multicolumn{3}{|c|}{$\mathrm{g} \mathrm{m}^{-2}$} & n/a \\
\hline \multirow[t]{4}{*}{ LAI } & Daepung & 3.93 & 3.88 & 0.37 & 0.96 & 379.7 & 412.7 & 79.93 & 0.96 \\
\hline & Daewon & 4.45 & 4.42 & 0.52 & 0.91 & 453.0 & 445.5 & 101.49 & 0.95 \\
\hline & Hengbuk & 4.30 & 4.29 & 0.83 & 0.77 & 400.7 & 411.5 & 39.25 & 0.99 \\
\hline & Poongsanamul & 4.08 & 4.06 & 0.55 & 0.90 & 439.9 & 431.9 & 86.91 & 0.94 \\
\hline \multirow[t]{4}{*}{$\mathrm{VI}^{\delta}$} & Daepung & 3.69 & 3.90 & 0.78 & 0.74 & 358.4 & 364.9 & 43.10 & 0.99 \\
\hline & Daewon & 3.93 & 4.31 & 0.73 & 0.70 & 418.9 & 458.9 & 105.54 & 0.93 \\
\hline & Hengbuk & 3.85 & 4.32 & 0.87 & 0.67 & 389.7 & 396.9 & 35.78 & 0.99 \\
\hline & Poongsanamul & 3.99 & 4.42 & 0.94 & 0.56 & 401.6 & 444.9 & 90.40 & 0.95 \\
\hline
\end{tabular}

$\delta$ VI stands for vegetation index.

Table A4. Error statistics of root mean square (RMSE) and Nash-Sutcliffe efficiency (NSE) in comparison between simulated and observed values of leaf area index (LAI) for soybean cultivars, simulated with the vegetation index input option for the RSCM regime using the data obtained at Jeonnam Agricultural Research and Extension Services in Naju, Chonnam province, South Korea in 2017.

\begin{tabular}{ccccc}
\hline \multirow{2}{*}{ Cultivar } & Simulated LAI & Observed LAI & RMSE & NSE \\
\cline { 2 - 4 } & \multicolumn{3}{c}{$\mathbf{m}^{\mathbf{2}} \mathbf{~ m}^{-2}$} & $\mathbf{n} / \mathbf{a}$ \\
\cline { 2 - 4 } & 3.42 & 3.53 & 1.47 & 0.61 \\
Daewon & 3.07 & 2.88 & 0.93 & 0.80 \\
Haepum & 3.49 & 2.96 & 1.16 & 0.68 \\
Poongsanamul & 3.17 & 2.91 & 1.17 & 0.45 \\
Taekwang & &
\end{tabular}

\section{References}

1. Mkhabela, M.S.; Bullock, P.; Raj, S.; Wang, S.; Yang, Y. Crop yield forecasting on the Canadian Prairies using MODIS NDVI data. Agric. For. Meteorol. 2011, 151, 385-393. [CrossRef]

2. Reeves, M.C.; Zhao, M.; Running, S.W. Usefulness and limits of MODIS GPP for estimating wheat yield. Int. J. Remote Sens. 2005, 26, 1403-1421. [CrossRef]

3. Doraiswamy, P.C.; Cook, P.W. Spring Wheat Yield Assessment Using NOAA AVHRR Data. Can. J. Remote Sens. 1995, 21, 43-51. [CrossRef]

4. Ahuja, L.R.; Rojas, K.W.; Hanson, J.D.; Shaffer, M.J.; Ma, L. Root Zone Water Quality Model: Modeling Management Effects on Water Quality and Crop Production; Water Resources Publications, LLC: Highland Ranch, CO, USA, 2000.

5. Ko, J.; Jeong, S.; Yeom, J.; Kim, H.; Ban, J.-O.; Kim, H.-Y. Simulation and mapping of rice growth and yield based on remote sensing. J. Appl. Remote Sens. 2015, 9, 096067. [CrossRef]

6. Azzari, G.; Jain, M.; Lobell, D.B. Towards fine resolution global maps of crop yields: Testing multiple methods and satellites in three countries. Remote Sens. Environ. 2017, 202, 129-141. [CrossRef]

7. Lobell, D.B.; Thau, D.; Seifert, C.; Engle, E.; Little, B. A scalable satellite-based crop yield mapper. Remote Sens. Environ. 2015, 164, 324-333. [CrossRef]

8. Haboudane, D.; Miller, J.R.; Pattey, E.; Zarco-Tejada, P.J.; Strachan, I.B. Hyperspectral vegetation indices and novel algorithms for predicting green LAI of crop canopies: Modeling and validation in the context of precision agriculture. Remote Sens. Environ. 2004, 90, 337-352. [CrossRef] 
9. Rondeaux, G.; Steven, M.; Baret, F. Optimization of soil-adjusted vegetation indices. Remote Sens. Environ. 1996, 55, 95-107. [CrossRef]

10. Zarco-Tejada, P.J.; Ustin, S.L.; Whiting, M.L. Temporal and spatial relationships between within-field yield variability in cotton and high-spatial hyperspectral remote sensing imagery. Agron. J. 2005, 97, 641-653. [CrossRef]

11. Hunt, E.R.; Hively, W.D.; Fujikawa, S.; Linden, D.; Daughtry, C.S.; McCarty, G. Acquisition of NIR-Green-Blue digital photographs from unmanned aircraft for crop monitoring. Remote Sens. 2010, 2, 290-305. [CrossRef]

12. Tucker, C.J.; Holben, B.N.; Elgin, J.H.; McMurtrey, J.E. Remote sensing of total dry-matter accumulation in winter wheat. Remote Sens. Environ. 1981, 11, 171-189. [CrossRef]

13. Moulin, S.; Bondeau, A.; Delecolle, R. Combining agricultural crop models and satellite observations: From field to regional scales. Int. J. Remote Sens. 1998, 19, 1021-1036. [CrossRef]

14. Yeom, J.-M.; Jeong, S.; Jeong, G.; Ng, C.T.; Deo, R.C.; Ko, J. Monitoring paddy productivity in North Korea employing geostationary satellite images integrated with GRAMI-rice model. Sci. Rep. 2018, 8, 16121. [CrossRef] [PubMed]

15. Jeong, S.; Ko, J.; Yeom, J.-M. Nationwide Projection of Rice Yield Using a Crop Model Integrated with Geostationary Satellite Imagery: A Case Study in South Korea. Remote Sens. 2018, 10, 1665. [CrossRef]

16. Zhiqiang, C.; Meng, J.; Wang, Y. Improving spring maize yield estimation at field scale by assimilating time-series HJ-1 CCD data into the WOFOST model using a new method with fast algorithms. Remote Sens. 2018, 8, 303.

17. Bouman, B.A.M. Linking physical remote sensing models with crop growth simulation models, applied for sugar beet. Int. J. Remote Sens. 1992, 13, 2565-2581. [CrossRef]

18. Maas, S.J. Parameterized model of gramineous crop growth: II. within-season simulation calibration. Agron. J. 1993, 85, 354-358. [CrossRef]

19. Maas, S.J. Parameterized model of gramineous crop growth: I. leaf area and dry mass simulation. Agron. J. 1993, 85, 348-353. [CrossRef]

20. Maas, S.J. GRAMI: A Crop Model Growth Model That Can Use Remotely Sensed Information; USDA-ARS: Washington, DC, USA, 1992; p. 78.

21. Ko, J.; Maas, S.J.; Lascano, R.J.; Wanjura, D. Modification of the GRAMI model for cotton. Agron. J. 2005, 97, 6. [CrossRef]

22. Martin, J.D.; Leonard, W.H.; Stamp, D.L.; Waldren, R.P. Principles of Field Crop Production, 4th ed.; Pearson Education, Inc.: Upper Saddle River, NJ, USA, 2005.

23. Jones, J.W.; Hoogenboom, G.; Porter, C.H.; Boote, K.J.; Batchelor, W.D.; Hunt, L.; Wilkens, P.W.; Singh, U.; Gijsman, A.J.; Ritchie, J.T. The DSSAT cropping system model. Eur. J. Agron. 2003, 18, 235-265. [CrossRef]

24. Jones, J.W.; Boote, K.J.; Hoogenboom, G.; Jagtap, S.S.; Wilkerson, G.G. SOYGRO V5.42. Soybean Crop Model Simulation Model. User's Guide; University of Florida \& International Benchmark Sites network for agrotechnology transfer, Florida Agri. Experi. Stat: Gainesville, FL, USA, Journal No. 8304; 1989; p. 75.

25. Wilkerson, G.G.; Jones, J.W.; Coble, H.D.; Gunsolus, J.L. SOYWEED: A Simulation Model of Soybean and Common Cocklebur Growth and Competition. Agron. J. 1990, 82, 1003-1010. [CrossRef]

26. Sinclair, T.R. Water and nitrogen limitations in soybean grain production I. Model development. Field Crop. Res. 1986, 15, 125-141. [CrossRef]

27. Setiyono, T.D.; Cassman, K.G.; Specht, J.E.; Dobermann, A.; Weiss, A.; Yang, H.; Conley, S.P.; Robinson, A.P.; Pedersen, P.; De Bruin, J.L. Simulation of soybean growth and yield in near-optimal growth conditions. Field Crop. Res. 2010, 119, 161-174. [CrossRef]

28. McCown, R.L.; Hammer, G.L.; Hargreaves, J.N.G.; Holzworth, D.P.; Freebairn, D.M. APSIM: A novel software system for model development, model testing and simulation in agricultural systems research. Agric. Syst. 1996, 50, 255-271. [CrossRef]

29. Kobayashi, H.; Ryu, Y.; Baldocchi, D.D.; Welles, J.M.; Norman, J.M. On the correct estimation of gap fraction: How to remove scattered radiation in gap fraction measurements? Agric. For. Meteorol. 2013, 174-175, 170-183. [CrossRef] 
30. Rouse, J.W., Jr.; Haas, R.H.; Schell, J.A.; Deering, D.W. Monitoring vegetation systems in the Great Plains with ERTS. Available online: https://ntrs.nasa.gov/archive/nasa/casi.ntrs.nasa.gov/19740022614.pdf (accessed on 1 November 2019).

31. Roujean, J.-L.; Breon, F.-M. Estimating PAR absorbed by vegetation from bidirectional reflectance measurements. Remote Sens. Environ. 1995, 51, 375-384. [CrossRef]

32. Monteith, J.L. Solar Radiation and Productivity in Tropical Ecosystems. J. Appl. Ecol. 1972, 9, 747-766. [CrossRef]

33. Angus, J.F.; Cunningham, R.B.; Moncur, M.W.; Mackenzie, D.H. Phasic development in field crops I. Thermal response in the seedling phase. Field Crop. Res. 1980, 3, 365-378. [CrossRef]

34. Press, W.H.; Teukolsky, S.A.; Vetterling, W.T.; Flannery, B.P. Numerical Recipes: The Art of Scientific Computing; Cambridge University Press: New York, NY, USA, 1992.

35. Nash, J.E.; Sutcliffe, J.V. River flow forecasting through conceptual models part I-A discussion of principles. J. Hydrol. 1970, 10, 282-290. [CrossRef]

36. Wilson, J.W. Stand structure and light penetration. III. Sunlit foliage area. J. Appl. Ecol. 1967, 159-165. [CrossRef]

37. Sinclair, T.R.; Muchow, R.C. Radiation use efficiency. In Advances in Agronomy; Elsevier: Amsterdam, The Netherlands, 1999; Volume 65, pp. 215-265.

38. Collino, D.; Dardanelli, J.; Sereno, R.; Racca, R. Physiological responses of argentine peanut varieties to water stress: Light interception, radiation use efficiency and partitioning of assimilates. Field Crop. Res. 2001, 70, 177-184. [CrossRef]

39. Liu, X.; Rahman, T.; Yang, F.; Song, C.; Yong, T.; Liu, J.; Zhang, C.; Yang, W. PAR Interception and Utilization in Different Maize and Soybean Intercropping Patterns. PLoS ONE 2017, 12, e0169218. [CrossRef] [PubMed]

40. Reich, P.B.; Wright, I.J.; Lusk, C.H. Predicting leaf physiology from simple plant and climate attributes: A global GLOPNET analysis. Ecol. Appl. 2007, 17, 1982-1988. [CrossRef] [PubMed]

41. Dubey, P.; Raghubanshi, A.; Dwivedi, A.K. Relationship among specific leaf area, leaf nitrogen, leaf phosphorus and photosynthetic rate in herbaceous species of tropical dry deciduous in Vindhyan highlands. Ann. Plant Sci. 2017, 6, 1531-1536. [CrossRef]

42. Vile, D.; Garnier, E.; Shipley, B.; Laurent, G.; Navas, M.-L.; Roumet, C.; Lavorel, S.; Diaz, S.; Hodgson, J.G.; Lloret, F; et al. Specific Leaf Area and Dry Matter Content Estimate Thickness in Laminar Leaves. Ann. Bot. 2005, 96, 1129-1136. [CrossRef]

43. Grime, J.P.; Cornelissen, J.H.; Thompson, K.; Hodgson, J.G. Evidence of a causal connection between anti-herbivore defence and the decomposition rate of leaves. Oikos 1996, 3, 489-494. [CrossRef]

44. Maddonni, G.; Otegui, M.E.; Cirilo, A.G. Plant population density, row spacing and hybrid effects on maize canopy architecture and light attenuation. Field Crop. Res. 2001, 71, 183-193. [CrossRef]

45. Carpenter, A.; Board, J. Growth dynamic factors controlling soybean yield stability across plant populations. Crop Sci. 1997, 37, 1520-1526. [CrossRef]

46. Hirose, T. Development of the Monsi-Saeki theory on canopy structure and function. Annu. Bot. 2005, 95, 483-494. [CrossRef]

47. Ebadi, A.; Sajed, K.; Gharib-Eshghi, A. Evaluation of light extinction coefficient, radiation use efficiency and grain yield of soybean genotypes. Afr. J. Agric. Res. 2014, 9, 222-229.

48. Rosenberg, N.J.; Blad, B.L.; Verma, S.B. Microclimate: The biological environment; John Wiley and Sons: Hoboken, NJ, USA, 1983.

49. Bell, M.; Wright, G.; Harch, G. Environmental and agronomic effects on the growth of four peanut cultivars in a sub-tropical environment. I. Dry matter accumulation and radiation use efficiency. Exp. Agric. 1993, 29, 473-490. [CrossRef]

50. Nguyen, V.; Jeong, S.; Ko, J.; Ng, C.; Yeom, J. Mathematical integration of remotely-sensed information into a crop modelling process for mapping crop productivity. Remote Sens. 2019, 11, 2131. [CrossRef]

51. Šimunek, J.; Van Genuchten, M.T.; Šejna, M. HYDRUS: Model use, calibration, and validation. Trans. Asabe 2012, 55, 1263-1274.

52. Arnold, J.G.; Moriasi, D.N.; Gassman, P.W.; Abbaspour, K.C.; White, M.J.; Srinivasan, R.; Santhi, C.; Harmel, R.; Van Griensven, A.; Van Liew, M.W. SWAT: Model use, calibration, and validation. Trans. Asabe 2012, 55, 1491-1508. [CrossRef] 
53. Maas, S.J. Within-season calibration of modeled wheat growth using remote sensing and field sampling. Agron. J. 1993, 85, 669-672. [CrossRef]

54. Jeong, S.; Ko, J.; Choi, J.; Xue, W.; Yeom, J.-M. Application of an unmanned aerial system for monitoring paddy productivity using the GRAMI-rice model. Int. J. Remote Sens. 2018, 39, 2441-2462. [CrossRef]

55. Kim, H.-Y.; Ko, J.; Jeong, S.; Kim, J.-H.; Lee, B. Geospatial delineation of South Korea for adjusted barley cultivation under changing climate. J. Crop Sci. Biotechnol. 2017, 20, 417-427. [CrossRef]

(C) 2020 by the authors. Licensee MDPI, Basel, Switzerland. This article is an open access article distributed under the terms and conditions of the Creative Commons Attribution (CC BY) license (http://creativecommons.org/licenses/by/4.0/). 